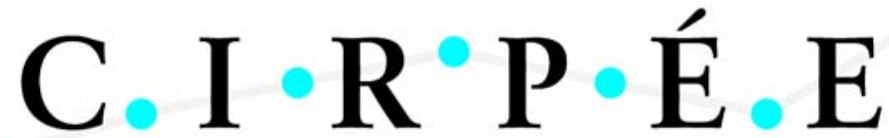

Centre Interuniversitaire sur le Risque, les Politiques Économiques et l'Emploi

Cahier de recherche/Working Paper 09-31

\section{Performance Analysis of a Collateralized Fund Obligation (CFO) Equity Tranche}

Shady Aboul-Enein

Georges Dionne

Nicolas Papageorgiou

Août/August 2009

Aboul-Enein: Alternative Investment Research Group, Desjardins Global Asset Management and HEC Montréal Dionne: Professor of Finance and Canada Research Chair in Risk Management, HEC Montréal and CIRPÉE. Corresponding author: HEC Montréal, Research Chair in Risk Management, 3000, Chemin de la Côte-SainteCatherine, Montréal, (QC) Canada H3T 2A7. Phone: +514 340-6596; Fax: +514 340-5019

georges.dionne@hec.ca

Papageorgiou: Professor of Finance, HEC Montréal, Director of Research, Desjardins Global Asset Management and CIRPÉE

We thank P. Ali, M. Crouhy, J. Grenier, A. Hocquard, V. Kapoor, E. Lefort and F. Longstaff for their comments and support. Claire Boisvert and Lewina Giles improved the presentation of this article. This research was financed by the Canada Research Chair in Risk Management and the Alternative Investment Research Group, Desjardins Global Asset Management. 


\begin{abstract}
:
This article examines the performance of the junior tranche of a Collateralized Fund Obligation (CFO), i.e. the residual claim (equity) on a securitized portfolio of hedge funds. We use a polynomial goal programming model to create optimal portfolios of hedge funds, conditional to investor preferences and diversification constraints (maximum allocation per strategy). For each portfolio we build CFO structures that have different levels of leverage, and analyze both the stand alone performance as well as potential diversification benefits (low systematic risk exposures) of investing in the Equity Tranche of these structures. We find that the unconstrained mean-variance portfolio yields a high performance, but greater exposure to systematic risk. We observe the exact opposite picture in the case of unconstrained optimization where a skewness bias is added, thus proving the existence of a trade-off between stand alone performance and low exposure to systematic risk factors. We provide evidence that leveraged exposure to these hedge fund portfolios through the structuring of CFOs creates value for the Equity Tranche investor.
\end{abstract}

Keywords: Collateralized Fund Obligation (CFO), hedge funds, structured finance, portfolio optimization, performance analysis, multivariate linear regression, systematic risk.

JEL Classification: G11, G23 


\section{INTRODUCTION}

In 2002, structured finance and hedge funds merged together for the first time. This union gave birth to Collateralized Fund Obligations (CFO) which consists in the securitization of hedge fund portfolios. This new category of asset seems to offer the best of both worlds. On the one hand it provides investors with a new vehicle through which to obtain exposure to hedge fund returns, and on the other hand offers to the financial engineers a new and quite unique pool of assets that they could securitize. The variety of strategies and low correlations with traditional assets make hedge funds an ideal candidate as collateral for securitization transactions. Although the theoretical justification of CFOs has been firmly established in financial literature (See Cheng (2002), Mahadevan and Schwartz (2002), Stone and Zissu (2004) and Missinhoun and Chacowry (2005)), there are still many misgivings as to their practical pertinence.

Thus, despite the rapid growth of the CDO market over the past two decades, there were no more than 20 CFO transactions prior to 2008. A lack of interest by investors in the Equity Tranche of these structures seems to be the source of the slow proliferation. The perception of low added-value and high inherent leverage, made it difficult to solicitate interest in the junior tranche of CFOs. That said, given the novelty and the complexity of these products, which belong to a vast family of derivatives, it is logical to suppose that the distinctive fundamental characteristics and benefits of the exposure to a CFO Equity Tranche have yet to be carefully scrutinized. This article provides a thorough analysis of the factors that might influence the performance of various hypothetical CFO Equity Tranches. Using data on historical hedge fund returns, the goal is to structure various CFOs based on a variety of underlying portfolios and investigate the returns of the Equity Tranche both in terms of stand alone performance and in terms of potential diversification benefits.

More specifically, the first objective, from the viewpoint of a CFO equity owner, is to define the optimal capital structure(s) as well as the general attributes for the diversification of the optimal portfolio of hedge funds for the securitization transaction. 
The analysis is therefore far more thorough than that observed in existing literature on the subject of CFOs. In order to investigate the impact of strategy selection and diversification in the underlying hedge fund portfolio, we implement an optimization model that allows us to specify preferences for higher moments. This polynomial goal programming approach generates optimal allocations conditional to specific investor preferences. For each "optimal" portfolio, several debt structures are then considered so as to account for a far broader range of scenarios. This is done in order to identify, on the basis of a number of performance indicators, the optimal composition of the collateral and the appropriate leverage to which the exposure should be subjected.

The second objective is to study the exposure of the CFO Equity Tranche to systematic risk factors, such as market, credit and liquidity. In this sense, the study will determine the degree to which returns are defined by the returns of readily available risk premia, and therefore provide a better idea of their risk exposures. This is achieved using a multivariate linear regression model.

The results indicate that CFOs create value from the equity holder's perspective. Nonetheless, there is a trade-off that must be made between the stand alone performance of a CFO Equity Tranche and its' systematic risk exposure. We find that the unconstrained mean-variance portfolio yields a high performance but exhibits greater exposure to systematic risk factors. We observe the exact opposite in the case of unconstrained optimization where a preference for skewness is incorporated, thus proving the existence of a trade-off between performance and low-correlation with the financial markets. According to our results, an interesting compromise could be obtained by securitizing a well-diversified (constrained) underlying portfolio of funds.

The article is structured as follows. Section 2 presents the three stage methodology. Section 3 describes and analyzes the data and Section 4 focuses on the empirical results. Conclusions are presented in Section 5. 


\section{MethODOLOGY}

The methodology is comprised of three steps. The first step concerns the allocation of hedge funds across the different strategies, the second relates to the structuring and evaluation of the CFO, and the final stage consists in the analysis of the systematic risk exposures of the resulting Equity Tranche of the CFO.

\subsection{Allocation across hedge fund strategies}

To decide on the asset allocation between the different investment strategies we use a polynomial goal programming (PGP) optimization model. This approach was introduced by Tayi and Leonard (1988), and has been employed by Chunhachinda, Dandapani, Hamid, and Prakash (1997) and Sun and Yan (2003) to incorporate the effect of skewness on portfolio allocation decisions. Davies, Kat, and Lu (2009) use this approach to incorporate investor preferences for higher moments into the construction of funds of funds. They extend the original model in order to account not only for skewness but also for the kurtosis that is prevalent in hedge fund return distributions. This approach incorporates multiple, and often conflicting, objectives and considers the impact of a change in investor preferences on asset allocation.

\subsubsection{The PGP model}

Consider an environment with $m$ risky assets, each with random return $\tilde{R}_{i}$, and $x_{i}$ being the percentage of wealth invested in the $i^{\text {th }}$ asset. The risk free rate $r$ is constant and no short selling of the risky assets is permitted. The percentage invested in the risk-free asset is determined by $x_{m+1}=1-I^{\top} \mathbf{X}$, where $\mathbf{I}$ is an identity vector of dimension $m \times 1$ and $\mathbf{X}$ is the vector of dimension $m \times 1$ of percentages of wealth invested in the risky assets. $V$ is the variance-covariance matrix for $\tilde{\boldsymbol{R}}=\left(\tilde{R_{1}}, \tilde{R_{2}}, \ldots, \tilde{R_{m}}\right)$. This matrix is positive and of dimension $m \times m$. Thus, the problem of portfolio selection can be defined using the PGP model:

$$
\begin{array}{ll}
\text { MIN } & Z=\left(1+d_{1}\right)^{\alpha}+\left(1+d_{3}\right)^{\beta}+\left(1+d_{4}\right)^{\gamma} \\
\text { Subject to } & E\left[\mathbf{X}^{\top} \tilde{\boldsymbol{R}}\right]+x_{\mathrm{m}+1} r+d_{1}=Z_{1}^{*},
\end{array}
$$




$$
\begin{aligned}
& E\left[\mathbf{X}^{\top}(\tilde{\boldsymbol{R}}-E[\tilde{\boldsymbol{R}}])\right]^{3}+d_{3}=Z_{3}^{*}, \\
& -E\left[\mathbf{X}^{\top}(\tilde{\boldsymbol{R}}-E[\tilde{\boldsymbol{R}}])\right]^{4}+d_{4}=-Z_{4}^{*}, \\
& d_{1}, d_{3}, d_{4} \geq 0, \\
& \mathbf{X}^{\top} \mathbf{V X}=1, \quad x_{\mathrm{i}} \geq 0, \quad x_{\mathrm{m}+1}=1-\mathrm{I}^{\top} \mathbf{X},
\end{aligned}
$$

where $Z_{1}^{*}=\operatorname{Max}\left\{Z_{1} \mid \mathbf{X}^{\top} \mathbf{V X}=1\right\}$ is the average return of the optimal mean-variance portfolio with a unit variance, $Z_{3}^{*}=\operatorname{Max}\left\{Z_{3} \mid \mathbf{X}^{\top} \mathbf{V X}=1\right\}$ is the skewness of the optimal skewness-variance portfolio with a unit variance, and $Z_{4}^{*}=\operatorname{Max}\left\{Z_{4} \mid \mathbf{X}^{\top} \mathbf{V X}=1\right\}$ is the kurtosis of the optimal kurtosis-variance portfolio with a unit variance; and where $\alpha, \beta$ and $\gamma$ are non-negative parameters specific to the investor's subjective degree of preference with respective regard to the average, the skewness and the kurtosis of the portfolio's returns. The form of the objective function ensures its monotone growth in $d_{1}$, $d_{3}$ et $d_{4}$ for all possible values.

Even though the technique does not require an investor-specific utility function, it can still be inferred that the investors' utility functions are of higher order than quadratic. Importantly, the model's parameters $\alpha, \beta$ and $y$ have an explicit economic interpretation; they are directly linked to the concept of the marginal rate of substitution, which measures the desirability of foregoing an objective for the purpose of achieving another (trade-off of objectives). In short, the problem of a multi-objective PGP is solved in two stages. Firstly, the optimal values for $Z_{1}^{*}, Z_{3}^{*}$ and $Z_{4}^{*}$ are each obtained within a twodimensional unit variance framework. Subsequently, these values are substituted in conditions (2) through (4) and the minimum value of (1) is found for a given set of investor preferences $\{\alpha, \beta, \gamma\}$ within a four-moment framework.

All resulting portfolios are composed of risky assets (hedge fund strategies) and a riskfree asset so as to ensure the unicity of each optimal portfolio. In order to ensure that the portfolio is solely invested in hedge funds, one must simply redistribute the allocation in the risk-free rate to the hedge fund strategies such that the total investment in the 
risky assets equals 1 . Thus $y_{i}=x_{i} /\left(x_{1}+x_{2}+\ldots+x_{m}\right)$ will be the percentage invested in the $i^{\text {th }}$ asset (hedge fund strategy $i$ ) for the optimal portfolio $Y$.

Five sets of preference parameters $\{\alpha, \beta, \gamma\}$ are used for the optimization procedure. These are: $E_{1}=\{\alpha=1, \beta=0, \gamma=0\}, E_{2}=\{\alpha=1, \beta=1, \gamma=0\}, E_{3}=\{\alpha=1, \beta=1, \gamma=0.75\}$, $E_{4}=\{\alpha=2, \beta=1, \gamma=0.75\}$ and $E_{5}=\{\alpha=3, \beta=1, \gamma=0.25\}$. The goal is not to build portfolios with fully-representative parameters, but to determine the relative importance that must be attributed to each of the higher-order moments of the distribution. Simultaneously, one of the main objectives is to characterize an optimal underlying portfolio from the viewpoint of a CFO equity owner and it is therefore reasonable to suppose that the five sets of preferences should easily suffice. Note that the preference set $E_{1}$ represents a traditional mean-variance optimization. We also perform constrained optimizations for each set of preferences, with maximum allocation to each strategy limited to $10 \%, 15 \%, 20 \%, 25 \%$ and 50\%. Finally, given the recent empirical evidence supporting equally-weighted portfolio (for example DeMiguel, Garlappi and Uppal (2005)) we also consider the $(1 / \mathrm{m})$ portfolio allocation. In all 31 portfolios will be analyzed. The notation that will be employed to refer to a given preference set and diversification constraint is $E_{h k}$, where $h$ refers to the preference set and $k$ to the maximum allocation per strategy.

\subsection{CFO Structures}

In constructing the CFO structures we follow the approach of Mahadevan and Schwartz (2002). Overall, 20 structures are analysed, with each $\mathrm{CFO}_{\mathrm{j}}(j=1,2, \ldots, n)$ being distinguished by its debt-to-equity ratio. $\mathrm{CFO}_{1}$ represents the zero-debt case, which is simply a direct, unleveraged exposure to the hedge fund portfolio ${ }^{1}$. The amount of debt within the structure is then increased in increments of $5 \%$ for each of the ensuing CFO structures, up to $\mathrm{CFO}_{20}$ in which the Equity Tranche represents only $5 \%$ of the structure. Table 1 presents the 20 structures.

\footnotetext{
${ }^{1}$ Costs related to the structure's management and debt obviously do not apply in the case of this instrument.
} 


\section{$<$ Table 1>}

Each CFO has a par value of $\$ 400 \mathrm{M}$ and a maturity of 7 years $^{2}$. As the proportion of debt increases, we notice that the number of tranches of rated debt also increases. To this end, a number of assumptions are made so as to comply with a same economic logic across all structures. We therefore assume that the first 200 million in debt (50\% of the structure) are senior rated (AA), which explains why no junior debt tranche appears prior to $\mathrm{CFO}_{12}$. This new tranche (BBB) is capped at $20 \%$ of the structure ( $\left.\$ 80 \mathrm{M}\right)$, so that when more than $\$ 280 \mathrm{M}$ in debt accrues, the BB tranche of debt is added. This new tranche is capped at $15 \%$. The final tranche (BB-) only appears in the two riskiest structures, i.e. which use the most leverage.

It is important to note that the model does not include a coupon rate for each of the tranches. Instead, the procedure uses an "aggregated" cost of financing expressed in basis points in relation to a benchmark index that reflects the total, periodic remuneration of creditors, i.e. the owners of the CFO's rated debt tranches. Therefore, the greater the number of tranches, the greater the structure's financing costs. Indeed, with regard to structures whose debt represents $50 \%$ or less, the cost of financing is 150 basis points over the 1-month LIBOR. For the two structures that use the most leverage, the cost is 450 basis points more than the benchmark rate. Thus, this increased cost of capital on a per-level basis illustrates the need for increased returns on the underlying portfolio as the structure's leverage increases. Simultaneously, this aspect of a convex increase in costs (150 to $200 \mathrm{bps}, 200$ to $300 \mathrm{bps}, 300$ to $450 \mathrm{bps}$ ) allows us to observe the risk associated with the junior debt tranches.

The common costs underlying our CFO structures differ slightly from those of Mahadevan and Schwartz (2002). Specifically, the periodic cost of debt is directly calculated by adding the variation in basis points for each level to the 1-month LIBOR rate. Consequently, it is assumed that the structures are perfectly hedged in terms of interest rate risk, which reduces the number of variables handled without however undermining the robustness of the analysis. The senior management fees of $0.5 \%$ per

\footnotetext{
${ }^{2}$ These are representative of the size and maturity of a typical CFO transaction.
} 
annum and the up-front fees of 3\% add to the financial burden of the structure's liabilities. To prevent the up-front fees from disproportinately impacting the first month's results, the latter are financed by the structure via a gradually-amortized loan at the 7year Swap rate in effect at the time the vehicle is issued (5.85\%). For the $\$ 12 \mathrm{M}$ million originally due ( $3 \% \times \$ 400 \mathrm{M})$, the monthly installment amounts to $\$ 174,441$.

Thus, from the above information and a series of returns on a collateralized portfolio, it is possible to derive a periodic return on the Equity Tranche of any structure for any underlying portfolio. To calculate the monthly return of the Equity Tranche of $\mathrm{CFO}_{\mathrm{j}}$, hk at time $t$ using the return on $E_{\mathrm{hk}}$, the following formulas are used:

$$
\begin{gathered}
\text { Equity }_{j, h k, t}=\left\{\left[N A V_{t-1}\left(1+r_{h k, t}\right)-D_{j}\left(\frac{\text { LIBOR }_{t}+A F C_{j}}{12}\right)-\left(N A V_{t-1} * \frac{0,5 \%}{12}\right)-P M T\right]-D_{j}\right\} \\
r_{j, h k, t}=\frac{\text { Equity }_{j, h k, t}-\text { Equity }_{j, h k, t-1}}{\text { Equity }_{j, h k, t-1}}
\end{gathered}
$$

where:

Equity $_{j, h k, t}$ is the value of the equity of the structure $j, h k$ at the end of month $t$; $N A V_{t-1}$ is the structure's total value at the beginning of the month $t$; $r_{h k, t}$ is the return on portfolio $E_{h k}$ for the month $t$; $D_{j}$ is the value of the debt of $\mathrm{CFO}_{j}$;

$L_{I B O R_{t}}$ is the value of the 1-month LIBOR at the end of month $t$; $A F C_{j}$ is the aggregated financing cost of $\mathrm{CFO}_{\mathrm{j}}$;

$0.5 \% / 12$ corresponds to the senior management fees reported monthly; PMT corresponds to the monthly payment of $\$ 174,441$ concerning the amortization of up-front fees.

A monthly frequency is favored herein; all costs are therefore reported on a monthly basis and the income generated by the model is represented by a series of returns, each with 84 observations ( 7 years $\times 12$ months). It is also important to mention that contrary to Mahadevan and Schwartz (2002), no distribution of market value gains will be performed during the 7 years of the vehicles' existence. Implicitly, the assumption of 
a 7-year lock-up period is in effect with regard to the equity owners. In short, this model is not intended as a perfect representation of the operations observed in practice; the objective herein is to record our findings with regard to the performance of the Equity Tranche in relation to the structure's leverage and the composition of the underlying portfolio. Therefore, the assumptions put forward do not prevent us from meeting this objective. The model presented, which is purposely simple and robust, enables us to meet the objectives of our process without encumbering the analysis with the CFO's structural details.

\subsubsection{Evaluating the Equity Tranche}

Given the 31 hedge fund portfolios and 20 possible CFO structures, we obtain 620 series of returns $(31 \times 20$ CFO structures) containing 84 observations each.

An initial analysis of the results is performed using a number of performance measures. In addition to calculating the usual descriptive statistics and normality tests for return distributions $^{3}$, several performance measures are calculated to evaluate the riskadjusted performance of the different CFO structures. We employ two conventional measures, specifically, the Sharpe and Treynor ratios. We also calculate three more comprehensive measures, namely the Sortino ratio (see Sortino and Price (2004)), the modified Sharpe ratio (see Gregoriou and Gueyi (2003) and Lee (2007)) and the Omega measure (see Keating and Shadwick (2002) and De Souza and Gokcan (2004)).

In sum, after having determined the CFO structures and optimal portfolios from the equity owner's viewpoint using the performance measures stated above, the attributes of capital structure (D/E ratio) and the impact of the diversification constraints on the underlying strategies are analyzed. These results allow us to draw a first round of conclusions.

\footnotetext{
${ }^{3}$ For a complete description of the tests of normality used, refer to Jarque and Bera (1980), Lilliefors (1967) and Genest and Rémillard (2004).
} 


\subsection{Analysis of the Systematic Risk Exposure}

In order to verify whether the Equity Tranche of each CFO is exposed to systematic risk factors (market, credit and liquidity) we estimate a multivariate linear regression. If the resulting regression coefficients are not significant, this would imply that returns on CFO Equity Tranches are not determined by systematic risk fators and hence could offer significant diversification benefits to traditional portfolios. The same analysis is performed on the returns of the underlying hedge fund portfolios so as to compare the diversification benefits resulting from a direct exposure to the hedge fund portfolios versus that of a CFO. The variables for the regression are presented in Section 4.3.

\section{DATA}

The hedge fund data was provided by Desjardins Global Asset Management and includes HFR and TASS databases. As of January 31, 2008, 7,533 hedge funds were included in the database. The sample consists of monthly returns of hedge funds over a period of 17 years, from February 1991 to January 2008. The database includes specific information about each fund, including the self-reported investment style.

Of the original 7,533 hedge funds, many had to be eliminated from the study. Firstly, 2,523 funds of hedge funds were withdrawn because they are not strategy-specific funds. Similarly, $126 \mathrm{HFRI}$ and HFRX indexes were deleted. Next, we eliminated 73 funds that did not report their after-fee returns. Also, to ensure the reliability of data used and avoid dealing with self-selection bias, 632 funds were withdrawn from the sample as they registered either less than 12 consecutive months of performance or the disclosure of their results had been interrupted at some point. Finally, 33 "Regulation D" funds were discarded since the latter category only appears as of the late ' 90 s.

Given that this article focuses on the optimal allocation of capital across the various hedge fund strategies, it is necessary to further examine the distribution of funds across the strategies. We observe that across the 29 initial strategies, certain strategies have 
more than 300 funds while others have less than 30. To address this relative imbalance, we opt to aggregate similar strategies. After these deletions and aggregations, the returns of 4,146 hedge funds make up the sample over a period of 204 months (17 years $\times 12$ months). Table 2 presents the distribution of hedge funds across strategies before and after aggregation.

$<$ Table2>

We observe that the process results in three new aggregated strategies: Emerging markets (Asia, E. Europe/CIS, Global and Latin America), Fixed Income (Arbitrage, Convertible Bonds, Diversified, High Yield and Mortgage Backed) and Sectorial (Energy, Financial, Health Care/Biotechnology, Miscellaneous, Real Estate and Technology). The number of strategies therefore decreases from 29 to 16 and the hedge funds are subsequently better dispersed across the strategies.

In order to circumvent the issue of relative size of the strategies, avoid working with 4,146 assets and further counter the issue of survivorship bias, an equally-weighted index is constructed for each strategy. In other words, an average return per strategy is calculated for each date of the sample. This allows us to perform the portfolio optimization with 16 assets and obtain easily-interpretable results in relation to the number, attributed weight and type of the different strategies so as to create the greatest possible value for the owners of a CFO Equity Tranche. Hence, from a technical point of view, this approach ensures the investment in active (or living) funds for each of the strategies without exposure to the specific risk of a given fund. This therefore avoids periodically rolling funds, allowing us to maintain the necessary weights, i.e. to put forward a passive management strategy.

Furthermore, in order to meet the objectives of the proposed empirical approach, the sample is split into two periods. The first ten years of the sample are used for the optimization of hedge fund portfolios ex ante, and the final seven years provide out-of- 
sample data to which the CFO structures will be applied. Table 3 presents the statistics of each strategy index over the first ten years and over the final seven years.

\section{$<$ Table 3>}

If we first make a general comparison between the data of the two periods, we note that hedge fund returns over period 1 are higher, more volatile and generally demonstrate a greater level of skewness and kurtosis. This result can mainly be explained by the fact that period 1 witnessed a very bullish market while period 2 was more unpredictable and generated less value on the financial markets ${ }^{4}$. In this regard, it should be noted that the data only cover the beginning of the 2008 financial crisis. Nonetheless, despite the obvious disparities between the two periods, the strategies demonstrate similar behavior. We observe that the tests of Jarque-Bera, Lilliefors, and Genest and Remillard reject normality in the respective proportions of $81 \%(13 / 16), 56 \%(9 / 16)$ and $63 \%$ (10/16) for period 1 and 38\% (6/16), 38\% (6/16) and 56\% (9/16) for period 2. This must be considered when testing the normality of returns of the constructed portfolios and CFOs.

As for the comparison between the strategies themselves, we first observe that the Emerging Markets and Sectorial strategies demonstrate the best average monthly returns while the Short Selling strategy is at the bottom of the ladder. In terms of volatility, the above three strategies are, quite logically, at the top of the list, alongside with the Equity Non-Hedge and Managed Futures strategies while the majority of market-neutral strategies demonstrate the least volatile returns. Secondly, Foreign Exchange strategy stands out with its positive skewness while the Merger Arbitrage and Event Driven strategies are distinguished by higher kurtosis. When the time comes to dissect the composition of the optimal portfolios, it will be interesting to analyze the weight assigned in light of these preliminary descriptive statistics.

\footnotetext{
${ }^{4}$ The Dow Jones Industrial Average Index recorded an increase of approximately 300\% (14.9\% on an annual basis) between February 1991 and January 2001, and less than 20\% (2.5\% on an annual basis) between February 2001 and January 2008.
} 
Several other financial time series covering the period over which the CFO structures are distributed (2001-2008) are required to perform all the necessary calculations. These series, all expressed on a monthly basis, are obtained from Bloomberg. Table 4 summarizes the descriptive statistics for these secondary variables. The 1-month LIBOR and $T$-bill series both have the same average, but the returns on the latter are far more volatile. The 10-year on- and off-the-run government securities demonstrate almost identical statistical behavior while 20-year on-the-run securities offer better average returns and are less volatile. Finally, we note that these three assets exhibit positive skewness (with the exception of the Russell 3000).

$<$ Table 4>

\section{EMPIRICAL RESULTS}

\subsection{Optimal hedge fund allocations}

Table 5 presents, for three of the sets of preferences $E_{h}=\{\alpha, \beta, \gamma\}$, the composition of the optimized hedge fund portfolios. ${ }^{5}$ We observe, conditional on the diversification constraint imposed, the weight $y_{i}$ assigned to each strategy.

\section{$<$ Table 5>}

In analyzing the various distributions, we notice first of all that in the case of meanvariance optimization ( $\alpha=1, \beta=0, y=0$ ), with no weight constraint, one-third of capital is allocated to Relative Value Arbitrage and Foreign Exchange strategies, respectively. This is logical since these two strategies have the highest reward-risk ratios for period 1 , i.e. the time window allotted for the optimization process. As the diversification constraint on the optimized portfolio is increased, the Equity Hedge and Distressed Securities strategies represent the majority of the composition, with the two previous strategies situated at the highest possible level permissible under the said constraint. It should be noted here that the two least constrained portfolios are identical. This means that even if

\footnotetext{
${ }^{5}$ For the purpose of brevity, only the results for preference sets $E_{1}, E_{2}$ and $E_{3}$ are presented in Tables 5 and 6 .
} 
we allow weights in excess of $50 \%$ of the portfolio, no portfolio will be positioned above this threshold for this set of preferences.

With regard to the set of preferences $E_{2}=\{\alpha=1 ; \beta=1 ; \gamma=0\}$, there is equal preference between returns and skewness; with no importance placed on the level of kurtosis. When the weights $y_{i}$ are unconstrained, almost $45 \%$ of the capital is allocated to Foreign Exchange strategy, i.e. the one with greatest level of positive skewness. However, it may be surprising to see that the Equity Market Neutral and Convertible Arbitrage strategies, which are both negatively skewned, are ranked second and third respectively. This clearly demonstrates the trade-off between skewness and returns for this preference set. It is also interesting to note that as the maximum weight constraint becomes more significant, thereby forceably reducing the allocation in the Foreign Exchange strategy, the allocation to Equity Market Neutral and Convertible Arbitrage strategies practically disappear. It is at this point that the Equity Hedge, Distressed Securities, Market Timing, Short Selling and Managed Futures strategies start to emerge. These strategies all exhibit positive skewness and lower skewness-return ratios.

As for $E_{3}=\{\alpha=1, \beta=1, \gamma=0.75\}$, the relative significance of the kurtosis is evident for the first time. In this case, we note a more harmonious balance of funds across strategies from the very outset. Despite this, the Foreign Exchange strategy is still predominant (20\% in the least-constrained case) along with Distressed Securities (13\%) and Market Timing (16\%). No other strategy obtains more than $10 \%$ of the capital. This allocatrion certainly takes root in the weak kurtosis observed in relation to the significance of the skewness levels of the three main strategies. For this set of preferences, the evolution of diversification constraints has very little impact on the allocation of capital. In this regard, it will be interesting to compare the performance of these portfolios, where there is optimal allocation through all strategies, to that of equally-weighted funds that allocate the same proportion of capital to each strategy. 


\subsubsection{Performance Analysis}

Table 6 presents the descriptive statistics, the tests of normality and the performance measures attributable to the returns of the portfolios examined in period 2. These results are presented for the same sets of preferences as presented earlier, and for the equallyweighted portfolio.

\section{$<$ Table 6>}

In analyzing Table 6 with regard to the descriptive statistics for each series of returns, we first see that they are in line with those of their main components, i.e. the strategy indexes. For example, the funds of the set $E_{2}$ demonstrate the greatest level of skewness and the non-weight-constrained mean-variance portfolio dominates in terms of the return-variance ratio. These characteristics become diluted as diversification broadens, while the presence of other strategies gradually normalizes the allocations. It is also interesting to note that the equally-weighted portfolio demonstrates the best average returns and the most variance. In this sense, it is not surprising to see average returns decrease with the diversification of the set of preferences $E_{1}$ while variance also shows a sharp decrease. However, this same phenomenon does not apply to the other optimized portfolios for which allocation considers both skewness and kurtosis. In short, the mean of all average returns is 0.79 and there is mostly negative skewness and positive excess kurtosis.

With regard to the normality of returns, we first notice that normality is not rejected in all cases according to the Jarque-Bera test. With respect to the other two tests, the returns of five portfolios out of 31 (16.1\%) reject the assumption of normality under the Lilliefors test, while six out of $31(19.4 \%)$ do the same when the Genest and Remillard procedure is used. This is an interesting result. Although most hedge fund strategy indexes reject normality on an individual level, it would appear that when these strategies are combined together, the distributions of the portfolios are considerably more Gaussian. Let us also recall that the strategy indexes exhibit greater normality in period 2, which may be another plausible explanation. In sum, without completely casting aside rejection of the null hypothesis, the decrease in the proportion of rejections is undisputable. 
These results may seem small for a hedge fund environment, but they are still significant and confirm the relevance of using comprehensive performance measures, or at least those measures that account for all information contained in the tails of the distributions. It is also interesting to emphasize that normality is only rejected in the case of highlydiversified portfolios; the normality of returns of the equally-weighted portfolio is rejected by the Lilliefors, and Genest and Remillard tests.

With regard to traditional performance measures, it is the unconstrained portfolio of set $E_{1}$ that has the highest Sharpe ratio at 0.80 while the equally-weighted portfolio comes in last at 0.61 . For the other portfolios, the value of the Sharpe ratio varies between 0.62 and 0.67. Consequently, it appears that no distinction can be made between the portfolios using this performance measure. On the other hand, the unconstrained portfolios of sets $E_{2}$ and $E_{5}$ stand out in terms of the best Treynor ratio with a value of around 0.80 and 0.20 , respectively. Their good performance in terms of Treynor ratio is largely due to the low beta coefficient, i.e. the covariance of returns with those of the market. It should once again be noted that the equally-weighted portfolio has the lowest ratio at 0.04 . In sum, if we base the analysis on the Sharpe and Treynor ratios, we would conclude that incorporating preferences for higher moments does not generate value. Equal weighting is systematically an underperforming strategy and diversification generally undermines the performance of a hedge fund portfolio.

If we focus on the more comprehensive performance measures, it is possible to better evaluate and discern the advantages of accounting for higher moments. It should be noted here that for the Sortino ratio and the Omega measure, the monthly minimal accepted returns (MAR) used for the calculations are $0.8 \%$ and $1.2 \%$. Table 7 summarizes the performance for all portfolios with regard to the comprehensive performance measure. In addition, a classification of each measure is included.

$<$ Table 7> 
For the Sortino ratio and the Omega measure, the equally-weighted portfolio dominates, which is the exact opposite of the observation made using the two simple performance measures. Also, we deduce that equal weighting may be better than the highlydiversified optimizations found using the PGP model. This is similar to the conclusions of DeMiguel, Garlappi and Uppal (2005). Nevertheless, certain funds originating from the optimization procedure are always among the best performers. As for the lowest values, the unconstrained portfolios for the set of preferences $E_{2}$ and $E_{5}$ are ranked near the bottom, which directly contradicts the results of the Treynor ratio presented earlier. The mean-variance optimal portfolio (preference set $E_{1}$ ) no longer outperforms.

The modified Sharpe ratio offers a similar classification as the conventional Sharpe ratio. Unlike the Omega measure, the modified Sharpe ratio simply incorporates estimates of the skewness and kurtosis coefficients. It does not incorporate all information regarding the actual empirical distribution. Nonetheless, given the non-normality of the returns distributions of certain portfolios, this version of the ratio allows us to establish a more precise classification of the different portfolios of funds.

In short, there are seven portfolios that stand out from our performance analysis. These are: $E_{1 ; 100 \%}, E_{2 ; 100 \%}, E_{2 ;} 20 \%, E_{4 ; 10 \%}, E_{5 ; 50 \%,} E_{5 ; 15 \%}$ and $E_{6 ; 6.25 \%}$. It is clear that the underlying interests appear at two extremes of diversification. Indeed, they are either very little or highly diversified, which means that no unilateral deduction can be made unless it accounts for investor preference. In the following section, we shall determine whether these findings still apply from the viewpoint of a CFO equity owner.

\subsection{Performance of the CFOs' Equity Tranche}

Table 8 presents the results of the equity of CFO structures 11,15 and 18 . These structures are those deemed optimal from the viewpoint of junior tranche owners. That said, the following remarks arise from the study of all of the structures. As in the previous section, the descriptive statistics, the results of tests of normality and the performance measures are included. 


\section{$<$ Table 8>}

In analyzing the descriptive statistics, we observe that regardless of the securitized underlying portfolio, the linear increase of leverage within a CFO structure results in a relatively linear increase, at least at the outset, of the first four centered moments of the distribution of equity returns. This finding seems logical a priori. However, for a given aggregate cost of financing, where the maximum debt level has been reached, average returns seem to experience a local peak.

With regard to tests of normality, we see that the Jarque-Bera, Lilliefors, and Genest and Remillard tests reject normality in the respective proportions of 5\% (28/589), $17 \%$ (102/589) and 21\% (125/589). In all three cases, this represents an increase compared to the case of unlevered portfolio of hedge funds, which reinforces the interest of using more comprehensive performance measures. Generally speaking, it is possible to conclude that the securitization of hedge funds reduces the normality of the return distribution of the Equity Tranche. When we look more closely at the distribution of "nonnormality" across structures, we see a more frequent rejection of the null hypothesis as the structure's leverage increases. Indeed, we note for example that using the method of Genest and Remillard, four out of 31 funds rejected the normality of equity returns in the case of CFO 2; the result is ten out of 31 for CFO 14.

As for the performance indicators, we will focus on the more sophisticated measures. First of all, the Sortino ratio increases as leverage increases, reaching a maximum for CFO 15, for both levels of minimal accepted returns considered. In the case of the unconstrained mean-variance portfolio, the measure is close to 1 with a monthly MAR at $0.8 \%$, and 0.82 with a monthly MAR at $1.2 \%$. Beyond CFO 15 , the ratio decreases toward the weaker levels of CFO 20. According to this measure however, there seems to be an optimal debt level for the equity owner, beyond which it is no longer beneficial to add leverage. With regard to the measure's overall behavior as leverage increases, we once again observe the phenomenon of local peaks for CFOs 11 and 18 . 
The Omega measure behaves in a similar manner to the Sortino ratio except for the fact that it decreases beyond a certain threshold when we consider a monthly MAR $=0.8 \%$. More specifically, when the minimal accepted return is at this level, the maximum occurs at CFO 18 for a value of almost 1.96, and CFOs 11 and 15 are also distinguished by their local optimality. With monthly MAR $=1.2 \%$, CFO 20 shows the highest values at levels above 1.40. However, if we compare this structure to that of CFO 18, we see that the highest values are very close and that the lowest values of CFO 20 are substantially lower than those of CFO 18. Thus, the benefits of leverage decrease for CFOs 19 and 20. In summary, the three structures using a maximum level of debt still dominate, thus CFOs 11, 15 and 18. Also, it is interesting to note that at this level of minimal accepted returns, it is the equally-weighted portfolio that results in maximum "intra-CFO" values rather than the portfolios resulting from the unconstrained optimization.

Finally, the modified Sharpe ratio behaves much the same way as the conventional Sharpe ratio. It systematically decreases between CFO 2 and CFO 20, and the rate at which the decrease occurs for CFOs 12, 16 and 19 is far more pronounced. The estimates of the higher moments used in the calculation of the modified Sharpe ratio are however subject to significant estimation error as the size of the sample is relatively small. Ultimately, we will rely exclusively on the Sortino and Omega measures given that they account more accurately for the actual empirical distribution of the returns.

In short, the performance analysis indicates that CFOs 11, 15 and 18, which maximize the debt levels for a given aggregate cost CFO structures, are clearly distinguished from the others. The optimal debt-to-equity ratios are therefore $1,7 / 3$ and $17 / 3$. For every dollar of equity, there must be at least one dollar of debt. In this sense, this supports the existence of an optimal debt level from the equity owner's viewpoint, the merit of CFOs and thus, the added-value of the latter for the investor. These results also show the outperformance of the CFO Equity Tranche, regardless of the structure, when compared to a direct exposure to the portfolio of hedge funds. Indeed, if we compare the results of the Sortino ratio and the Omega measure from one portfolio of hedge funds to another versus the CFO, the latter always outperform the former. It is important to emphasize 
that if we rely solely on simple performance measures, we would not come to these conclusions.

With regard to the relationship between the underlying portfolio and the performance of the CFO Equity Tranche, the results show more or less the same pattern as in the previous section. More specifically, the funds all behave in a similar manner from the equity owner's viewpoint, regardless of the amount of leverage. This means that the same seven portfolios are of interest to the CFO Equity Tranche owner and that once again, on the sole basis of risk-adjusted performance, no general conclusion can be drawn as to the diversification requirements for an equity owner. It all depends on the objectives pursued. As a result, there appears to be independence between decisions concerning the underlying portfolio and the debt structure. This is indeed very interesting as CFOs are flexible instruments, meaning that it is possible to choose the types of underlying portfolio according to one's need for diversification and the extent of leverage based on one's appetite for risk.

In short, from an initial universe of 589 potential CFOs, the number is now a mere 21. Indeed only seven portfolios and three structures are of interest. By including the unlevered hedge fund portfolios as CFO 1, we test the systematic risk exposure of 28 of the 620 initial instruments using a multivariate linear regression model.

\subsection{Systematic Risk Exposure of the Equity Tranche}

The following multivariate linear regression model for the verification of the benefits of diversification was estimated using the returns of the 28 CFO structures identified in the previous section.

$\mathrm{CFO}_{j, h k, t}=\delta_{j, h k, t}+\beta_{1 j, h k} \mathrm{STOCK}_{t}+\beta_{2 j, h k} \mathrm{DEF}_{t}+\beta_{3 j, h k} \mathrm{LIQ}_{t}+\beta_{4 j, h k} \mathrm{TERM}_{t}+\beta_{5 j, h k} \mathrm{TREND}_{t}+\varepsilon_{j, h \mathrm{k}}$ where:

$\delta_{j, h k, t}$ is the constant term for the $\mathrm{CFO}_{\mathrm{j}}$, subjected to the set of preference $E_{\mathrm{h}}$ and the diversification constraint $k$, at time $t$; 
$\mathrm{CFO}_{\mathrm{j}, \mathrm{hk}, \mathrm{t}}$ is the monthly return of $\mathrm{CFO}_{\mathrm{j}}$, constructed using the hedge fund portfolio subjected to the set of preference $E_{\mathrm{h}}$ and the diversification constraint $k$, at time $t$.

STOCK $_{\mathrm{t}}$ is the monthly return of the Russel 3000 stock index at time $t$. It is used as an indicator of financial market performance and is included so as to determine whether systematic exposure to equity returns has an explicative power with regard to the performance of a securitized hedge fund portfolio.

DEF $F_{t}$ is the spread in basis points of the LUCI Total OAS ${ }^{6}$ index at time $t$ and is used as an indicator of the systematic default risk of credit markets. It is included in the model so as to ascertain whether systematic default risk in the credit markets influences CFO returns. To this end, several variables are used in the literature to capture this notion of default. However, as stipulated in Longstaff, Mithal and Neis (2005), among others, since the advent of the Credit Default Swaps (CDS) market, it has become common practice to use the spreads on these instruments to identify the default risk embedded in credit risk ${ }^{7}$.

$\mathrm{LIQ}_{t}$ is the spread in basis points between 10-year on-the-run and off-the-run government securities at time $t$. The variable is used as an indicator of the systematic liquidity risk of bond markets. This indicator is further explained in Longstaff, Mithal and Neis (2005).

TERM $_{t}$ is the spread in basis points between long-term (20-year) and short-term (1month t-bills) government securities at time $t$. It is used as an indicator of systematic interest rate risk. This indicator is the same as that used in Fama and French (1993).

\footnotetext{
${ }^{6} \mathrm{LUCl}$ is the acronym for Liquid US Corporate Indices, a series of bond indexes developed by Crédit Suisse. The Total OAS (Option Adjusted Spread) version captures the entire market, eliminating the specific nature of securities such as embedded options.

7 The original intention was to use the CDX.NA.IG index spread. However, a thorough study of the series shows that there is a lack of liquidity prior to 2004 , which could bias the results.
} 
TREND $_{t}$ is the typical time trend that is used when the variables are distributed over time. The idea is to eliminate any time trend effect that may result in autocorrelation in the data series.

Table 9 presents the value of the estimated coefficients and their respective $p$-value. We recall that the ideal scenario is that of completely uncorrelated returns, i.e. statistically null coefficients. In the case of the constant $\delta_{j, h k, t}$ its statistical significance implies the presence of a fixed effect not captured by the model's variables.

\section{$<$ Table 9>}

We first note that the constant $\delta_{j, h k, t}$ and the coefficient $\beta_{5}$, which is attributed to the TREND variable, are always significant. This means, on the one hand, that returns are specific to each of the instruments. In addition, we see that the values taken by $\delta_{j, h k, t}$ are always positive and increase as leverage increases, thus reflecting greater added-value. On the other hand, the significance of $\beta_{5}$ confirms that there is indeed a trend in terms of CFO returns. It is also interesting to note that this coefficient is always negative, implying that returns decrease over the period studied (2001-2008).

When we consider the estimated coefficients of the variables of interest, $\beta_{1}$ to $\beta_{4}$, it is important to emphasize at the very outset that the statistical significance of the coefficients follows a rather consistent pattern across the different CFO structures tested. Indeed, the same pattern in terms of the statistical significance of the regression coefficients is exhibited in the case of direct exposure to the portfolio of hedge fund and CFO 11, whereas CFOs 15 and 18 present fewer significant coefficients. It can therefore be inferred that leverage has very little effect on systematic diversification. The benefits of diversification are therefore not an argument in favor of CFOs.

Regardless of the choice of underlying portfolio and of the selected capital structure, the coefficient estimates indicate that the liquidity (LIQ) and slope of the term structure (TERM) variables do not significantly impact CFO returns. With respect to the STOCK variable, which relates to systematic equity market risk, we note that the estimated 
coefficient is almost always significant. The estimated coefficient for the default risk variable is less stable across the different CFO structures. In the case of exposure to CFO 1 and CFO 11, we see that the DEF variable has a significant, negative impact in the case of underlying portfolios $E_{1 ; 100 \%}, E_{2 ; 20 \%}$ and $E_{5 ; 15 \%}$. For CFOs 15 and 18, there is a gradual loss of significance of the estimated coefficient for the last two underlying portfolios $\left(E_{2 ; 20 \%}\right.$ et $\left.E_{5 ; 15 \%}\right)$.

Thus, it is the unconstrained mean-variance portfolio that fairs the most poorly in terms of systematic risk exposures, while the unconstrained version of preference set $E_{2}$ demonstrates the least dependence to the selected systematic risk factors. We recall however that this underlying portfolio underperforms in terms of most performance measures. It therefore appears necessary to reach a compromise between performance and decorrelation with the capital market as the best of both worlds can not be achieved simultaneously. Two interesting alternatives appear to be that of $E_{4 ; 10 \%}$ and the equallyweighted portfolio that both exhibit a slight positive correlation with equity markets. Although not an optimal solution, these results provide strong evidence that it is possible to construct CFOs that generate value in terms of both performance and low systematic risk exposure.

On the basis of the results above, when the objective pursued by the investor in terms of CFO equity is either performance, or decorrelation, an unconstrained portfolio in which Foreign Exchange strategy is predominant is essential. Where one wishes to combine the two objectives, there must be substantial diversification of the underlying portfolio. With regard to the debt-to-equity ratio of the capital structure selected, there is almost no impact, notwithstanding exceptions. This therefore implies that CFOs represent addedvalue compared to a direct exposure to the portfolio of hedge funds, only in terms of performance however, not with regard to diversification in capital markets. 


\section{CONCLUSION}

In response to suggestions that CFO Equity Tranches do not offer value to investors, we decided to undertake a thorough examination of the performance of this type of investment. The objective was to assess the performance of the Equity Tranche of CFOs both in terms of risk-adjusted return as well as systematic risk exposures. For this purpose, 30 optimal portfolios (each conditional to a set of preferences and weight constraints) and an equally-weighted portfolio were constructed using 16 hedge fund strategy indexes. All of these underlying portfolios were then securitized using 19 capital structures, which allowed us to analyze the series of returns of 620 CFO Equity Tranches.

Interestingly, we observe that if we consider the overall distribution of returns of a CFO Equity Tranche in analyzing the performance, securitizing and tranching the underlying portfolio of hedge funds adds value for the end investor. Our analysis also finds that there was no direct relationship between the optimal portfolio to securitize and the capital structure decisions. With regard to the debt-to-equity ratio, we conclude that leverage is beneficial for the CFO equity holder when the level of debt is maximized for a given funding cost. In addition, our analysis shows that a trade-off takes place between performance and systematic diversification; if one considers a combination of the two objectives, we conclude that the underlying portfolio must be broadly diversified across the various hedge fund strategies. Thus, these conclusions suggest that market participants might have been too hasty in dismissing CFOs, and not taking greater advantage of the benefits offered by these investment vehicles.

If the reputation of securitization had not already been undermined by its involvement in the current financial crisis, the impact of this two-dimensional analysis could have been rather different. However, given the present stigma attached to structured products, we should not expect to witness new CFO transactions anytime soon. This is unfortunate considering that the nature of the problem is one of inaccurate valuation rather than one of overexuberant financial engineering, as explained in Longstaff and Myers (2009). 
Global financial markets are currently seeking to rebuild a sound financial system and it will be interesting to see whether CFOs will be favored among the range of investments available to institutional investors. For this to transpire, securitization and financing practices must be rehabilitated in conjunction with proper governance rules that promote greater transparency.

Since it is only a matter of time before financial markets have had the chance to digest the consequences of the current crisis, it is relevant to pursue this research further. Under this new analysis, it would be consistent to consider alternative ways in which to further expand on the conclusions. For example, an actively-managed underlying portfolio could be of interest. Indeed, rather than turning to strategy indexes that are not readily investible, it would be suitable to use investments in specific funds and make readjustments as necessary. From a risk management viewpoint, it would be appropriate to examine the potential tools that would allow exposure to a CFO Equity Tranche to provide strong risk-adjusted performance with negligible exposure to systematic risk factors. Finally, it would be important to assess the impact of high market stress (like the one that prevailed in 2007 and 2008) in order to analyze the behavior of CFOs in such circumstances. 


\section{REFERENCES}

Amin, G. S., and H. M. Kat. "Hedge Fund Performance 1990-2000: Do the Money Machines Really Add Value?", Journal of Financial and Quantitative Analysis, (2003), 38(2):251-275.

Amin, G. S., and H. M. Kat. "Stocks, Bonds and Hedge Funds: Not a Free Lunch!", Working paper, ICMA Centre, University of Reading, Berkshire (2002).

Boakye, C. "Multidimensional Risk/Performance Measurement for Hedge Funds.", Working paper, Temple University's MSFE program, Philadelphia (2008).

Cheng, C. "Securitization \& Hedge Funds: Creating a More Efficient Market.", Working paper, Intangis, Renaissance Capital Group, New York (2002).

Chunhachinda, P.; K. Dandapani; S. Hamid; and A. Prakash. "Portfolio Selection and Skewness: Evidence from International Stock Markets.", Journal of Banking and Finance, 21 (1997), 143167.

Davies, R. J.; H. M. Kat; and S. Lu. "Fund of Hedge Funds Portfolio Selection: A MultipleObjective approach.", Journal of Derivatives and Hedge Funds, Forthcoming (2009).

DeMiguel, A-V.; L. Garlappi; and R. Uppal. "How Inefficient are Simple Asset-Allocation Strategies?", Working paper, London Business School, Centre for Economic Policy Research, London (2005).

De Souza, C., and S. Gokcan. "Allocation Methodologies and Customizing Hedge-Fund MultiManager Multi-Strategy Products.", Journal of Alternative Investments, 6 (2004), 7-21.

Fama, E., and K. French. "Common Risk Factors in the Returns on Stocks and Bonds.", Journal of Financial Economics, 33 (1993), 3-56.

Fung, W., and D. A. Hsieh. "Asset Based Style Factors for Hedge Funds.", Financial Analysts Journal, 58 (2002), 16-27.

Genest, C., and B. Rémillard (2004). "Tests of Independence and Randomness Based on the Empirical Copula Process.", Test, Sociedad de Estadistica e Investigacion Operativa, 13 (2004), 335-369.

Gregoriou, G. N., and J-P. Gueyie. "Risk-Adjusted Performance of Funds of Hedge Funds using a Modified Sharpe Ratio.", Journal of Wealth Management, 6 (2003), 77-83.

Jarque, C. M., and A. K. Bera. "Efficient Tests for Normality, Homoscedasticity and Serial Independence of Regression Residuals.", Economic Letters, 6 (1980), 255-259.

Keating, C., and W. F. Shadwick. "A Universal Performance Measure.", Working paper, The Finance Development Centre, London (2002).

Lilliefors, H. W. "On the Kolmogorov-Smirnov Test for Normality with Mean and Variance Unknown.", Journal of the American Statistical Association, 62 (1967), 399-402. 
Lee, S. L. "Modified VAR and the Allocation to Real Estate in the Mixed-Asset Portfolio.", International Real Estate Business School, University of Regensburg, Regensburg (2007)

Longstaff, F. A.; S. Mithal; and E. Neis. "Corporate Yield Spreads: Default Risk or Liquidity? New Evidence from the Credit-Default Swap Market.", Journal of Finance, 60 (2005), 2214-2254.

Longstaff, F. A., and B. Myers. "Valuing Toxic Assets: An Analysis of CDO Equity.", Working paper, NBER (2009).

Mahadevan, S., and D. Schwartz. "Hedge Fund Collateralized Fund Obligations." Journal of Alternative Investments, 5 (2002), 45-62.

Missinhoun, J., and L. Chacowry. "Collateralized Fund Obligations: The Value of Investing in the Equity Tranche.", Journal of Structured Finance, 10 (2005), 32-37.

Sharpe, W. F. "Mutual Fund Performance.", Journal of Business, 39 (1966), 119-138.

Sortino, F. A., and L. N. Price. "Performance Measurement in a Downside Risk Framework.", Journal of Investing, 3 (1994), 59-65.

Stone, C. A., and A. Zissu. "Fund of Fund Securitizations.", Journal of Derivatives, 11 (2004), 6269.

Sun, Q., and Y. Yan. "Skewness Persistence with Optimal Portfolio Selection.", Journal of Banking and Finance, 27 (2003), 1111-1121.

Tayi, G., and P. Leonard. "Bank Balance Sheet Management: An Alternative Multiobjective Model." Journal of Operations Research Society, 39 (1988), 401-410.

Treynor, J. L. "How to Rate Management of Investment Funds.", Harvard Business Review, 43 (1965), 63-75. 


\section{Structural Assumptions for the 20 CFOs Considered}

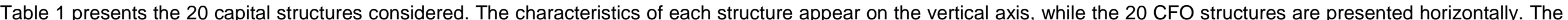

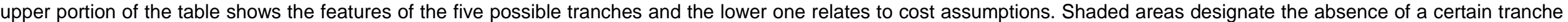
for a specific structure.

\begin{tabular}{|c|c|c|c|c|c|c|c|c|c|c|c|c|c|c|c|c|c|c|c|c|}
\hline & $\begin{array}{ll}\text { CFO } 1 \\
\end{array}$ & CFO 2 & CFO 3 & CFO 4 & CFO 5 & CFO 6 & CFO 7 & CFO 8 & CFO 9 & CFO 10 & CFO 11 & CFO 12 & CFO 13 & CFO 14 & CFO 15 & CFO 16 & CFO 17 & CFO 18 & CFO 19 & CFO 20 \\
\hline \begin{tabular}{|l|} 
Senior Notes \\
Rating \\
Par Value \\
$\%$ of tsucture \\
Advance Rate
\end{tabular} & 菂 & $\begin{array}{l}\mathrm{AA} \\
\$ 20 \mathrm{M} \\
5 \% \\
60 \%\end{array}$ & $\begin{array}{c}\text { AA } \\
\$ 40 \mathrm{M} \\
10 \% \\
60 \%\end{array}$ & $\begin{array}{l}\text { AA } \\
\$ 60 \mathrm{M} \\
155 \% \\
60 \%\end{array}$ & $\begin{array}{l}\mathrm{AA} \\
\$ 80 \mathrm{M} \\
20 \% \\
60 \%\end{array}$ & $\begin{array}{c}\text { AA } \\
\$ 100 \mathrm{M} \\
25 \% \\
60 \%\end{array}$ & $\begin{array}{c}\mathrm{AA} \\
\$ 120 \mathrm{M} \\
30 \% \\
60 \%\end{array}$ & $\begin{array}{c}\mathrm{AA} \\
\$ 140 \mathrm{M} \\
35 \% \\
60 \%\end{array}$ & $\begin{array}{c}\text { AA } \\
\$ 160 \mathrm{M} \\
40 \% \\
60 \%\end{array}$ & $\begin{array}{c}\text { AA } \\
\$ 180 \mathrm{M} \\
45 \% \\
60 \%\end{array}$ & $\begin{array}{c}\mathrm{AA} \\
\$ 200 \mathrm{M} \\
50 \% \\
60 \%\end{array}$ & $\begin{array}{c}\text { AA } \\
\$ 200 \mathrm{M} \\
50 \% \\
60 \%\end{array}$ & $\begin{array}{c}\text { AA } \\
\$ 200 \mathrm{M} \\
50 \% \\
60 \%\end{array}$ & $\begin{array}{c}\text { AA } \\
\$ 200 \mathrm{M} \\
50 \% \\
60 \%\end{array}$ & $\begin{array}{c}\mathrm{AA} \\
\$ 200 \mathrm{M} \\
50 \% \\
60 \%\end{array}$ & $\begin{array}{c}\mathrm{AA} \\
\$ 200 \mathrm{M} \\
50 \% \\
60 \%\end{array}$ & $\begin{array}{c}\mathrm{AA} \\
\$ 200 \mathrm{M} \\
50 \% \\
60 \%\end{array}$ & $\begin{array}{c}\mathrm{AA} \\
\$ 200 \mathrm{M} \\
50 \% \\
60 \%\end{array}$ & $\begin{array}{c}\mathrm{AA} \\
\$ 200 \mathrm{M} \\
50 \% \\
60 \%\end{array}$ & $\begin{array}{c}\text { AA } \\
\$ 200 \mathrm{M} \\
50 \% \\
60 \%\end{array}$ \\
\hline $\begin{array}{l}\text { Class II Notes } \\
\text { Rating } \\
\text { Par Value } \\
\text { \% of Structure } \\
\text { Advance Rate }\end{array}$ & $\frac{ㅇ ㅡ ㅇ ~}{\frac{9}{2}}$ & & & & & & & & & & & $\begin{array}{c}\text { BBB } \\
\$ 20 \mathrm{M} \\
5 \% \\
75 \%\end{array}$ & $\begin{array}{l}\text { BBB } \\
\$ 40 \mathrm{M} \\
10 \% \\
75 \%\end{array}$ & $\begin{array}{l}\text { BBB } \\
\$ 60 \mathrm{M} \\
155 \% \\
75 \%\end{array}$ & $\begin{array}{c}\text { BBB } \\
\$ 80 \mathrm{M} \\
20 \% \\
75 \%\end{array}$ & $\begin{array}{l}\text { BBB } \\
\$ 80 \mathrm{M} \\
20 \% \\
75 \%\end{array}$ & $\begin{array}{l}\text { BBB } \\
\$ 80 \mathrm{M} \\
20 \% \\
75 \%\end{array}$ & $\begin{array}{c}\text { BBB } \\
\$ 80 \mathrm{M} \\
20 \% \\
75 \%\end{array}$ & $\begin{array}{l}\text { BBB } \\
\$ 80 \mathrm{M} \\
200 \% \\
75 \%\end{array}$ & $\begin{array}{c}\text { BBB } \\
\$ 80 \mathrm{M} \\
20 \% \\
75 \%\end{array}$ \\
\hline $\begin{array}{l}\text { Class III Notes } \\
\text { Rating } \\
\text { Par Value } \\
\text { \% of Structure } \\
\text { Advance Rate }\end{array}$ & $\begin{array}{l}\frac{0}{2} \\
\frac{2}{3} \\
\frac{0}{2} \\
\frac{0}{x}\end{array}$ & & & & & & & & & & & & & & & $\begin{array}{c}\text { BB } \\
\$ 20 \mathrm{M} \\
5 \% \\
82 \%\end{array}$ & $\begin{array}{c}\mathrm{BB} \\
\$ 40 \mathrm{M} \\
10 \% \\
82 \%\end{array}$ & $\begin{array}{c}\text { BB } \\
\$ 60 \mathrm{M} \\
15 \% \\
82 \%\end{array}$ & $\begin{array}{c}\text { BB } \\
\$ 60 \mathrm{M} \\
15 \% \\
82 \%\end{array}$ & $\begin{array}{c}\text { BB } \\
\$ 60 \mathrm{M} \\
155 \% \\
82 \%\end{array}$ \\
\hline $\begin{array}{l}\text { Class IV Notes } \\
\text { Rating } \\
\text { Par Value } \\
\% \text { of Structure } \\
\text { Advance Rate }\end{array}$ & 菴 & & & & & & & & & & & & & & & & & & $\begin{array}{c}\mathrm{BB}- \\
\$ 20 \mathrm{M} \\
5 \% \\
90 \%\end{array}$ & $\begin{array}{c}\text { BB- } \\
\$ 40 \mathrm{M} \\
10 \% \\
90 \%\end{array}$ \\
\hline Total Debt & $\$$ & $\$ 20 \mathrm{M}$ & $\$ 40 \mathrm{M}$ & $\$ 60 \mathrm{M}$ & $\$ 80 \mathrm{M}$ & $\$ 100 \mathrm{M}$ & $\$ 120 \mathrm{M}$ & $\$ 140 \mathrm{M}$ & $\$ 160 \mathrm{M}$ & $\$ 180 \mathrm{M}$ & $\$ 200 \mathrm{M}$ & $\$ 220 \mathrm{M}$ & $\$ 240 \mathrm{M}$ & $\$ 260 \mathrm{M}$ & $\$ 280 \mathrm{M}$ & $\$ 300 \mathrm{M}$ & $\$ 320 \mathrm{M}$ & $\$ 340 \mathrm{M}$ & $\$ 360 \mathrm{M}$ & $\$ 380 \mathrm{M}$ \\
\hline $\begin{array}{l}\text { Equity Tranche } \\
\text { Par Value } \\
\% \text { of Structure } \\
\% \text { of MV Gains Distributed on a Current Basis }\end{array}$ & $\begin{array}{l}\$ 400 \mathrm{M} \\
100 \% \\
0 \%\end{array}$ & $\begin{array}{c}\$ 380 \mathrm{M} \\
95 \% \\
0 \%\end{array}$ & $\begin{array}{c}\$ 360 \mathrm{M} \\
90 \% \\
0 \%\end{array}$ & $\begin{array}{c}\$ 340 \mathrm{M} \\
85 \% \\
0 \%\end{array}$ & $\begin{array}{c}\$ 320 \mathrm{M} \\
80 \% \\
0 \%\end{array}$ & $\begin{array}{c}\$ 300 \mathrm{M} \\
75 \% \\
0 \%\end{array}$ & $\begin{array}{c}\$ 280 \mathrm{M} \\
70 \% \\
0 \%\end{array}$ & $\begin{array}{c}\$ 260 \mathrm{M} \\
65 \% \\
0 \%\end{array}$ & $\begin{array}{c}\$ 240 \mathrm{M} \\
60 \% \\
0 \%\end{array}$ & $\begin{array}{c}\$ 220 \mathrm{M} \\
55 \% \\
0 \%\end{array}$ & $\begin{array}{c}\$ 200 \mathrm{M} \\
50 \% \\
0 \%\end{array}$ & $\begin{array}{c}\$ 180 \mathrm{M} \\
45 \% \\
0 \%\end{array}$ & $\begin{array}{c}\$ 160 \mathrm{M} \\
40 \% \\
0 \%\end{array}$ & $\begin{array}{c}\$ 140 \mathrm{M} \\
35 \% \\
0 \%\end{array}$ & $\begin{array}{c}\$ 120 \mathrm{M} \\
30 \% \\
0 \%\end{array}$ & $\begin{array}{c}\$ 100 \mathrm{M} \\
25 \% \\
0 \%\end{array}$ & $\begin{array}{l}\$ 80 \mathrm{M} \\
20 \% \\
0 \%\end{array}$ & $\begin{array}{c}\$ 60 \mathrm{M} \\
15 \% \\
0 \%\end{array}$ & $\begin{array}{l}\$ 40 \mathrm{M} \\
10 \% \\
0 \%\end{array}$ & $\begin{array}{c}\$ 20 \mathrm{M} \\
5 \% \\
0 \%\end{array}$ \\
\hline Total Par Value of CFO & $\$ 400 \mathrm{M}$ & $\$ 400 \mathrm{M}$ & $\$ 400 \mathrm{M}$ & $\$ 400 \mathrm{M}$ & $\$ 400 \mathrm{M}$ & $\$ 400 \mathrm{M}$ & $\$ 400 \mathrm{M}$ & $\$ 400 \mathrm{M}$ & $\$ 400 \mathrm{M}$ & $\$ 400 \mathrm{M}$ & $\$ 400 \mathrm{M}$ & $\$ 400 \mathrm{M}$ & $\$ 400 \mathrm{M}$ & $\$ 400 \mathrm{M}$ & $\$ 400 \mathrm{M}$ & $\$ 400 \mathrm{M}$ & $\$ 400 \mathrm{M}$ & $\$ 400 \mathrm{M}$ & $\$ 400 \mathrm{M}$ & $\$ 400 \mathrm{M}$ \\
\hline DIE Ratio & - & 0.053 & 0.111 & 0.176 & 0.25 & 0.333 & 0.429 & 0.538 & 0.667 & 0.818 & 1.00 & 1.222 & 1.50 & 1.857 & 2.333 & 3.00 & 4.00 & 5.667 & 9.00 & 19.00 \\
\hline $\begin{array}{l}\text { Costs and Fees } \\
\text { All in Funding Cost (Spread in bps) } \\
\text { Senior Management Fee } \\
\text { Up-Front Fees } \\
\text { Benchmark } \\
7 \text {-year Swap rate @ } \mathrm{t}=0 \\
\end{array}$ & $\begin{array}{l}\text { N/A } \\
\text { N/A } \\
\text { N/A } \\
\text { N/A }\end{array}$ & $\begin{array}{c}150 \\
50 \mathrm{bps} \\
3 \% \\
1 \mathrm{M} L \mathrm{LBOR} \\
5.85 \% \\
\end{array}$ & $\begin{array}{c}150 \\
50 \text { bps } \\
3 \% \\
1 \mathrm{M} L \mathrm{LBOR} \\
5.85 \% \\
\end{array}$ & $\begin{array}{c}150 \\
50 \mathrm{bps} \\
3 \% \\
1 \mathrm{M} L \mathrm{LBOR} \\
5.85 \% \\
\end{array}$ & $\begin{array}{c}150 \\
50 \text { bps } \\
3 \% \\
1 \mathrm{MLBOR} \\
5.85 \% \\
\end{array}$ & $\begin{array}{c}150 \\
50 \mathrm{bps} \\
3 \% \\
1 \mathrm{M} L \mathrm{LBOR} \\
5.85 \% \\
\end{array}$ & $\begin{array}{c}150 \\
50 \mathrm{bps} \\
3 \% \\
1 \mathrm{ML} L \mathrm{LBOR} \\
5.85 \% \\
\end{array}$ & $\begin{array}{c}150 \\
50 \text { phs } \\
3 \% \\
1 \mathrm{MLLOR} \\
5.85 \% \\
\end{array}$ & $\begin{array}{c}150 \\
50 \mathrm{bps} \\
3 \% \\
1 \mathrm{M} L \mathrm{LBOR} \\
5.85 \% \\
\end{array}$ & $\begin{array}{c}150 \\
50 \mathrm{bps} \\
3 \% \\
1 \mathrm{M} L \mathrm{LBOR} \\
5.85 \% \\
\end{array}$ & $\begin{array}{c}150 \\
50 \text { phs } \\
3 \% \\
1 \mathrm{MLLOR} \\
5.85 \% \\
\end{array}$ & $\begin{array}{c}200 \\
50 \mathrm{bps} \\
3 \% \\
1 \mathrm{M} L \mathrm{LBOR} \\
5.85 \% \\
\end{array}$ & $\begin{array}{c}200 \\
50 \text { bps } \\
3 \% \\
1 \mathrm{M} L \mathrm{LBOR} \\
5.85 \% \\
\end{array}$ & $\begin{array}{c}200 \\
50 \mathrm{bps} \\
3 \% \\
1 \mathrm{M} L \mathrm{LBOR} \\
5.85 \% \\
\end{array}$ & $\begin{array}{c}200 \\
50 \mathrm{bps} \\
3 \% \\
1 \mathrm{M} L \mathrm{LBOR} \\
5.85 \% \\
\end{array}$ & $\begin{array}{c}300 \\
50 \mathrm{bps} \\
3 \% \\
1 \mathrm{M} L \mathrm{LBOR} \\
5.85 \% \\
\end{array}$ & $\begin{array}{c}300 \\
50 \mathrm{bps} \\
3 \% \\
3 \% \\
1 \mathrm{LLLOR} \\
5.85 \% \\
\end{array}$ & $\begin{array}{c}300 \\
50 \mathrm{bps} \\
3 \% \\
13 \% \text { LBOR } \\
5.85 \% \\
\end{array}$ & $\begin{array}{c}450 \\
50 \mathrm{bps} \\
3 \% \\
1 \mathrm{M} L \mathrm{LBOR} \\
5.85 \% \\
\end{array}$ & $\begin{array}{c}450 \\
50 \text { bps } \\
3 \% \\
1 \mathrm{M} L \mathrm{LBOR} \\
5.85 \% \\
\end{array}$ \\
\hline Stated Maturity (All Securities) & 7 Years & 7 Years & 7 Years & 7 Years & 7 Years & 7 Years & 7 Years & 7 Years & 7 Years & 7 Years & 7 Years & 7 Years & 7 Years & 7 Years & 7 Years & 7 Years & 7 Years & 7 Years & 7 Years & 7 Years \\
\hline
\end{tabular}




\section{Table 2}

\section{Distribution of Hedge Fund Strategies within Sample}

The table shows the absolute and relative frequencies of each of the hedge fund strategies in our sample. Panel A describes the sample before the aggregation of certain strategies while Panel B presents the sample after aggregation.

PANEL A

Sample BEFORE Strategy Aggregation

\begin{tabular}{|c|l|c|c|}
\hline & \multicolumn{1}{|c|}{ Strategy } & Frequency & $\begin{array}{c}\text { Relative } \\
\text { Frequency }\end{array}$ \\
\hline 1 & Convertible Arbitrage & 100 & $2.39 \%$ \\
2 & Distressed Securities & 112 & $2.68 \%$ \\
3 & Emerging Markets: Asia & 88 & $2.11 \%$ \\
4 & Emerging Markets: E. Europe/CIS & 71 & $1.70 \%$ \\
5 & Emerging Markets: Global & 109 & $2.61 \%$ \\
6 & Emerging Markets: Latin America & 26 & $0.62 \%$ \\
7 & Equity Hedge & 1359 & $32.52 \%$ \\
8 & Equity Market Neutral & 263 & $6.29 \%$ \\
9 & Equity Non-Hedge & 135 & $3.23 \%$ \\
10 & Event-Driven & 248 & $5.93 \%$ \\
11 & Fixed Income: Arbitrage & 75 & $1.79 \%$ \\
12 & Fixed Income: Convertible Bonds & 25 & $0.60 \%$ \\
13 & Fixed Income: Diversified & 86 & $2.06 \%$ \\
14 & Fixed Income: High Yield & 67 & $1.60 \%$ \\
15 & Fixed Income: Mortgage-Backed & 56 & $1.34 \%$ \\
16 & Foreign Exchange & 75 & $1.79 \%$ \\
17 & Macro & 293 & $7.01 \%$ \\
18 & Managed Futures & 299 & $7.15 \%$ \\
19 & Market Timing & 20 & $0.48 \%$ \\
20 & Merger Arbitrage & 37 & $0.89 \%$ \\
21 & Regulation D & 33 & $0.79 \%$ \\
22 & Relative Value Arbitrage & 288 & $6.89 \%$ \\
23 & Sector: Energy & 81 & $1.94 \%$ \\
24 & Sector: Financial & 33 & $0.79 \%$ \\
25 & Sector: Health Care/Biotechnology & 47 & $1.12 \%$ \\
26 & Sector: Miscellaneous & 35 & $0.84 \%$ \\
27 & Sector: Real Estate & 41 & $0.98 \%$ \\
28 & Sector: Technology & 58 & $1.39 \%$ \\
29 & Short Selling & 19 & $0.45 \%$ \\
\hline \hline & TOTAL & $\mathbf{4 1 7 9}$ & $\mathbf{1 0 0 \%}$ \\
\hline
\end{tabular}

PANEL B Sample AFTER Strategy Aggregation

\begin{tabular}{|c|l|c|c|}
\hline \multicolumn{1}{|c|}{ Strategy } & Frequency & $\begin{array}{c}\text { Relative } \\
\text { frequency }\end{array}$ \\
\hline 1 & Convertible Arbitrage & 100 & $2.41 \%$ \\
2 & Distressed Securities & 112 & $2.70 \%$ \\
3 & Equity Hedge & 1359 & $32.78 \%$ \\
4 & Equity Market Neutral & 263 & $6.34 \%$ \\
5 & Equity Non-Hedge & 135 & $3.26 \%$ \\
6 & Event-Driven & 248 & $5.98 \%$ \\
7 & Foreign Exchange & 75 & $1.81 \%$ \\
8 & Macro & 293 & $7.07 \%$ \\
9 & Managed Futures & 299 & $7.21 \%$ \\
10 & Market Timing & 20 & $0.48 \%$ \\
11 & Merger Arbitrage & 37 & $0.89 \%$ \\
12 & Relative Value Arbitrage & 288 & $6.95 \%$ \\
13 & Short Selling & 19 & $0.46 \%$ \\
14 & Emerging Markets & 294 & $7.09 \%$ \\
15 & Fixed Income & 309 & $7.45 \%$ \\
16 & Sectorial & 295 & $7.12 \%$ \\
\hline \hline
\end{tabular}




\section{Table 3}

\section{Statistics of Hedge Fund Strategy Indexes}

Table 3 presents the descriptive statistics and the results of the Jarque-Bera (JB), Lilliefors, and Genest-Remillard (G \& R) normality tests for every hedge fund strategy in the sample. Period 1 runs from February 1991 to January 2001, while period 2 covers the seven following years to January 2008. For both panels, the nature of the statistics appears on the left-hand-side and the strategies feature horizontally. The descriptive statistics are monthly and include the first four moments of the distributions, as well as the minimum and maximum returns. With regard to the tests for normality, the value of the test statistic and a dummy variable indicating whether or not the value is significant at a confidence level of $95 \%$ are presented*. The dummy variable equals 1 when the null hypothesis of normality is rejected.

\begin{tabular}{|c|c|c|c|c|c|c|c|c|c|c|c|c|c|c|c|c|}
\hline & \begin{tabular}{|c} 
Convert. \\
Arbit.
\end{tabular} & $\begin{array}{c}\text { Dist. } \\
\text { Securities }\end{array}$ & $\begin{array}{l}\text { Equity } \\
\text { Hedge }\end{array}$ & $\begin{array}{c}\text { E. Mkt } \\
\text { Neutral }\end{array}$ & $\begin{array}{c}\text { Equity N- } \\
\text { Hedge }\end{array}$ & $\begin{array}{l}\text { Event- } \\
\text { Driven }\end{array}$ & FX & Macro & $\begin{array}{c}\text { Mnged } \\
\text { Fut. }\end{array}$ & $\begin{array}{l}\text { Market } \\
\text { Timing }\end{array}$ & $\begin{array}{c}\text { Merger } \\
\text { Arbit. }\end{array}$ & $\begin{array}{c}\text { Relat. Val } \\
\text { Arbit. }\end{array}$ & $\begin{array}{l}\text { Short } \\
\text { Selling }\end{array}$ & $\begin{array}{c}\text { Emerg. } \\
\text { Mkts }\end{array}$ & Fixed Inc. & Sectorial \\
\hline Mean & 0.0119 & 0.0151 & 0.0180 & 0.0101 & 0.0165 & 0.0165 & 0.0161 & 0.0138 & 0.0146 & 0.0152 & 0.0118 & 0.0145 & -0.0039 & 0.0244 & 0.0109 & 0.0200 \\
\hline Standard deviation & 0.0116 & 0.0216 & 0.0273 & 0.0111 & 0.0355 & 0.0225 & 0.0206 & 0.0213 & 0.0456 & 0.0257 & 0.0118 & 0.0114 & 0.0828 & 0.0659 & 0.0114 & 0.0410 \\
\hline Skewness & -0.1963 & 0.9182 & 0.0413 & -0.2320 & -0.6419 & -0.5284 & 1.5295 & 0.2341 & 0.9591 & 0.7721 & -2.5619 & -0.7081 & 0.1929 & -0.1586 & -0.6013 & -0.5642 \\
\hline Kurtosis & 5.3599 & 7.4489 & 4.1026 & 2.5946 & 5.8056 & 8.8399 & 7.6032 & 3.9269 & 5.9506 & 4.9391 & 19.3466 & 4.501 & 4.8889 & 3.2656 & 6.2689 & 6.7705 \\
\hline Min & -0.0321 & -0.0647 & -0.0809 & -0.0195 & -0.1473 & -0.0948 & -0.0204 & -0.0561 & -0.0924 & -0.0464 & -0.0684 & -0.0230 & -0.3036 & -0.1946 & -0.0377 & -0.1733 \\
\hline Max & 0.0510 & 0.1086 & 0.1025 & 0.0338 & 0.1116 & 0.1094 & 0.1178 & 0.0826 & 0.2281 & 0.1154 & 0.0393 & 0.0402 & 0.2783 & 0.1874 & 0.0450 & 0.1399 \\
\hline $\mathrm{JB}$ Test $(\mathrm{df}=2)$ & 28.62 & 115.82 & 6.11 & 1.90 & 47.60 & 176.11 & 152.74 & 5.39 & 61.93 & 30.72 & 1467.32 & 21.30 & 18.58 & 0.86 & 60.66 & 77.45 \\
\hline$\alpha=5 \% ; x \leq 5.99$ & 1 & 1 & 1 & 0 & 1 & 1 & 1 & 0 & 1 & 1 & 1 & 1 & 1 & 0 & 1 & 1 \\
\hline Lilliefors Test & 0.007 & 0.001 & 0.50 & 0.02 & 0.50 & 0.16 & 0.001 & 0.17 & 0.04 & 0.16 & 0.008 & 0.003 & 0.008 & 0.50 & 0.10 & 0.01 \\
\hline$\alpha=5 \% ; p-v a l \geq 5 \%$ & 1 & 1 & 0 & 1 & 0 & 0 & 1 & 0 & 1 & 0 & 1 & 1 & 1 & 0 & 0 & 1 \\
\hline$G$ \& R Test & 0.00 & 0.00 & 0.89 & 0.09 & 0.59 & 0.01 & 0.00 & 0.19 & 0.01 & 0.06 & 0.00 & 0.00 & 0.00 & 0.95 & 0.04 & 0.02 \\
\hline$\alpha=5 \% ; p-v a l \geq 5 \%$ & 1 & 1 & 0 & 0 & 0 & 1 & 1 & 0 & 1 & 0 & 1 & 1 & 1 & 0 & 1 & 1 \\
\hline
\end{tabular}

\begin{tabular}{|c|c|c|c|c|c|c|c|c|c|c|c|c|c|c|c|c|}
\hline \multicolumn{17}{|c|}{ Period 2: 84 months (February 2001 to January 2008) } \\
\hline & \begin{tabular}{|c|} 
Convert. \\
Arbit.
\end{tabular} & $\begin{array}{c}\text { Dist. } \\
\text { Securities }\end{array}$ & $\begin{array}{l}\text { Equity } \\
\text { Hedge }\end{array}$ & $\begin{array}{l}\text { E. Mkt } \\
\text { Neutral }\end{array}$ & $\begin{array}{c}\text { Equity N- } \\
\text { Hedge }\end{array}$ & $\begin{array}{l}\text { Event- } \\
\text { Driven }\end{array}$ & FX & Macro & $\begin{array}{l}\text { Mnged } \\
\text { Fut. }\end{array}$ & $\begin{array}{l}\text { Market } \\
\text { Timing }\end{array}$ & $\begin{array}{c}\text { Merger } \\
\text { Arbit. }\end{array}$ & $\begin{array}{c}\text { Relat. Val } \\
\text { Arbit. }\end{array}$ & $\begin{array}{l}\text { Short } \\
\text { Selling }\end{array}$ & $\begin{array}{c}\text { Emerg. } \\
\text { Mkts }\end{array}$ & Fixed Inc. & Sectorial \\
\hline Mean & 0.0064 & 0.0114 & 0.0086 & 0.0056 & 0.0103 & 0.0089 & 0.0069 & 0.0094 & 0.0105 & 0.0064 & 0.0052 & 0.0085 & 0.0049 & 0.0167 & 0.0067 & 0.0113 \\
\hline Standard deviation & 0.0111 & 0.0134 & 0.0180 & 0.0064 & 0.0345 & 0.016 & 0.0099 & 0.0136 & 0.0279 & 0.0243 & 0.0086 & 0.0065 & 0.0470 & 0.0295 & 0.0083 & 0.0214 \\
\hline Skewness & -0.4950 & -0.1774 & -0.6148 & -1.2205 & -0.4870 & -0.7719 & 1.4167 & -0.0101 & -0.0549 & -0.0420 & -0.1752 & -0.6253 & 0.1632 & -0.9236 & -0.6435 & -0.3815 \\
\hline Kurtosis & 3.5464 & 3.2546 & 2.9455 & 5.7064 & 2.7287 & 3.6133 & 5.9688 & 2.7894 & 2.7363 & 2.5760 & 3.9317 & 3.6192 & 2.8247 & 3.3725 & 3.4356 & 2.5501 \\
\hline Min & -0.0284 & -0.0240 & -0.0414 & -0.0196 & -0.0774 & -0.0342 & -0.0067 & -0.0224 & -0.0570 & -0.0514 & -0.0210 & -0.0127 & -0.1013 & -0.0679 & -0.0176 & -0.0395 \\
\hline $\operatorname{Max}$ & 0.0339 & 0.0459 & 0.0444 & 0.0164 & 0.0774 & 0.0387 & 0.0444 & 0.0433 & 0.0719 & 0.0596 & 0.0260 & 0.0206 & 0.1281 & 0.0649 & 0.0236 & 0.0570 \\
\hline $\mathrm{JB}$ Test $(\mathrm{df}=2)$ & 4.48 & 0.67 & 5.30 & 46.49 & 3.58 & 9.66 & 58.95 & 0.16 & 0.29 & 0.65 & 3.47 & 6.82 & 0.48 & 12.43 & 6.46 & 2.75 \\
\hline$\alpha=5 \% ; x \leq 5.99$ & 0 & 0 & 0 & 1 & 0 & 1 & 1 & 0 & 0 & 0 & 0 & 1 & 0 & 1 & 1 & 0 \\
\hline Lilliefors Test & 0.12 & 0.18 & 0.05 & 0.02 & 0.07 & 0.003 & 0.006 & 0.50 & 0.50 & 0.38 & 0.02 & 0.13 & 0.39 & 0.001 & 0.09 & 0.15 \\
\hline$\alpha=5 \% ; p-v a l \geq 5 \%$ & 0 & 0 & 1 & 1 & 0 & 1 & 1 & 0 & 0 & 0 & 1 & 0 & 0 & 1 & 0 & 0 \\
\hline G \& R Test & 0.03 & 0.44 & 0.01 & 0.01 & 0.09 & 0.00 & 0.00 & 0.92 & 0.99 & 0.78 & 0.04 & 0.09 & 0.35 & 0.00 & 0.02 & 0.03 \\
\hline$\alpha=5 \% ; p-v a l \geq 5 \%$ & 1 & 0 & 1 & 1 & 0 & 1 & 1 & 0 & 0 & 0 & 1 & 0 & 0 & 1 & 1 & 1 \\
\hline
\end{tabular}

\footnotetext{
* P-values are available upon request.
} 


\section{Table 4}

\section{Descriptive Statistics of Secondary Data}

The table presents the first four moments of the distribution as well as the maximum and minimum. The statistics appear on the vertical axis, while the time series feature horizontally. They are all presented on a monthly return basis. $1 \mathrm{M} \mathrm{LIBOR}$ and $1 \mathrm{M}$ T-Bill are relative to the money market while the Russell 3000 is relative to the stock market. CDX.NA.IG_5Y and LUCI_OAS relate to the corporate credit market while the three whose title starts with USA are related to the U.S. government securities, 10- and 20-year maturities. For the 10-year maturity, on-the-run (on-t-r) and off-the-run (off-t-r) rates are presented.

\begin{tabular}{|c|c|c|c|c|c|c|c|c|}
\hline & LIBOR 1M & T-Bill 1M & Russel 3000 & CDX.NA.IG 5Y*a & LUCI OAS* & USA $10 Y$ (on-t-r) & USA $10 Y$ (off-t-r) & USA 20Y \\
\hline Mean & 0.0026 & 0.0026 & 0.0015 & 4.4948 & 12.0387 & 0.0037 & 0.0037 & 0.0042 \\
\hline Variance & 1.87E-06 & 5.10E-07 & 0.0016 & 1.5875 & 14.6199 & 1.50E-07 & $1.60 \mathrm{E}-07$ & 1.10E-07 \\
\hline Excess kurtosis & -1.6071 & -1.2216 & 0.3473 & 1.485 & -0.5299 & -0.4791 & -0.5402 & -0.5446 \\
\hline Max & 0.0048 & 0.0042 & 0.0803 & 9.0417 & 21.7833 & 0.0045 & 0.0045 & 0.0049 \\
\hline Min & 0.0009 & 0.0016 & -0.1064 & 2.5419 & 7.5167 & 0.0028 & 0.0028 & 0.0036 \\
\hline
\end{tabular}

Data are shown in terms of spread in basis points.

a The statistics relative to this series are calculated from 58 months of available data.

Table 5

\section{Composition of Optimal Portfolios for Sets of Preferences $E_{1}, E_{2}$ and $E_{3}$}

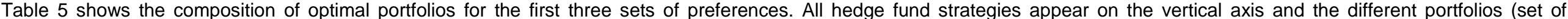

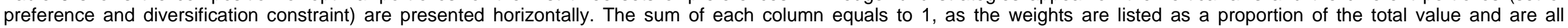
comprised between 0 and 1 (no-short constraint). Blanks refer to null allocations.

\begin{tabular}{|c|c|c|c|c|c|c|c|c|c|c|c|c|c|c|c|c|c|c|}
\hline \multirow{2}{*}{ HF Strategy } & \multicolumn{6}{|c|}{$E_{1}:\{\alpha=1 ; \beta=0 ; \gamma=0\}$} & \multicolumn{6}{|c|}{$E_{2}:\{\alpha=1 ; \beta=1 ; \gamma=0\}$} & \multicolumn{6}{|c|}{$E_{3}:\{\alpha=1 ; \beta=1 ; y=0.75\}$} \\
\hline & $y<=100 \%$ & $y<=50 \%$ & $y<=25 \%$ & $y<=20 \%$ & $y<=15 \%$ & $y<=10 \%$ & $y<=100 \%$ & $y<=50 \%$ & $y<=25 \%$ & $y<=20 \%$ & $y<=15 \%$ & $y<=10 \%$ & $y<=100 \%$ & $y<=50 \%$ & $y<=25 \%$ & $y<=20 \%$ & $y<=15 \%$ & $y<=10 \%$ \\
\hline Convertible Arbitrage & & & & 0.0267 & 0.0124 & 0.0828 & 0.1364 & 0.1372 & & 0.0150 & 0.0799 & 0.0775 & 0.0501 & 0.0501 & 0.0531 & 0.0510 & 0.0569 & 0.0659 \\
\hline Distressed Securities & 0.0941 & 0.0941 & 0.0988 & 0.1154 & 0.1500 & 0.1000 & & & 0.2500 & 0.2000 & 0.1500 & 0.1000 & 0.1326 & 0.1326 & 0.1347 & 0.1315 & 0.1340 & 0.1000 \\
\hline Equity Hedge & 0.1195 & 0.1195 & 0.2023 & 0.1579 & 0.1500 & 0.1000 & & & 0.1288 & 0.2000 & 0.1500 & 0.1000 & 0.0688 & 0.0688 & 0.0690 & 0.0678 & 0.0700 & 0.0792 \\
\hline Equity Market Neutral & & & & & & 0.0522 & 0.1780 & 0.1774 & & & 0.0579 & 0.0659 & 0.0488 & 0.0488 & 0.0566 & 0.0503 & 0.0574 & 0.0714 \\
\hline Equity Non-Hedge & & & & & & & & & & & & 0.0270 & 0.0154 & 0.0154 & 0.0133 & 0.0148 & 0.0197 & 0.0316 \\
\hline Event-Driven & 0.0175 & 0.0175 & & 0.0537 & 0.0484 & 0.0889 & & & & 0.0003 & & 0.0436 & 0.0360 & 0.0360 & 0.0247 & 0.0353 & 0.0367 & 0.0430 \\
\hline Foreign Exchange & 0.2986 & 0.2986 & 0.2500 & 0.2000 & 0.1500 & 0.1000 & 0.4418 & 0.4418 & 0.2500 & 0.2000 & 0.1500 & $\begin{array}{l}0.1000 \\
0.0454\end{array}$ & 0.2055 & 0.2055 & 0.2018 & 0.2000 & 0.1500 & 0.1000 \\
\hline $\begin{array}{l}\text { Macro } \\
\text { Managed Futures }\end{array}$ & & & & 0.0013 & 0.0106 & $\begin{array}{l}0.0077 \\
0.0241\end{array}$ & & & & & 0.1115 & $\begin{array}{l}0.0454 \\
0.1000\end{array}$ & 0.0538 & 0.0538 & $\begin{array}{l}0.0335 \\
0.0606\end{array}$ & 0.0602 & 0.0926 & $\begin{array}{l}0.0569 \\
0.0870\end{array}$ \\
\hline Market Timing & 0.0482 & 0.0482 & 0.0582 & 0.0829 & 0.1046 & 0.0926 & 0.0419 & 0.0421 & 0.2500 & 0.2000 & 0.1500 & 0.1000 & 0.1616 & 0.1616 & 0.1642 & 0.1633 & 0.1500 & 0.1000 \\
\hline Merger Arbitrage & 0.0524 & 0.0524 & 0.0645 & 0.0777 & 0.1074 & 0.0949 & 0.0931 & 0.0935 & 0.0050 & & 0.0226 & 0.0238 & 0.0226 & 0.0226 & 0.0253 & 0.0237 & 0.0248 & 0.0312 \\
\hline Relative Value Arbitrage & 0.3154 & 0.3154 & 0.2500 & 0.2000 & 0.1500 & 0.1000 & 0.0147 & 0.0157 & 0.0248 & 0.0271 & 0.0412 & 0.0531 & 0.0480 & 0.0480 & 0.0460 & 0.0488 & 0.0513 & 0.0572 \\
\hline Short Selling & 0.0344 & 0.0344 & 0.0475 & 0.0486 & 0.0629 & 0.0587 & 0.0307 & 0.0307 & 0.0914 & 0.1103 & 0.0850 & 0.0923 & 0.0739 & 0.0739 & 0.0681 & 0.0735 & 0.0782 & 0.0828 \\
\hline Emerging Markets & 0.0198 & 0.0198 & 0.0211 & 0.0128 & 0.0273 & 0.0271 & & & & 0.0209 & 0.0009 & 0.0153 & 0.0268 & 0.0268 & 0.0159 & 0.0257 & 0.0199 & 0.0209 \\
\hline Fixed Income & & & & & & 0.0204 & 0.0635 & 0.0616 & & & 0.0011 & 0.0295 & 0.0279 & 0.0279 & 0.0198 & 0.0278 & 0.0337 & 0.0417 \\
\hline Sectorial & & & 0.0077 & 0.023 & 0.0265 & 0.0505 & & & & 0.0265 & & 0.0266 & 0.0283 & 0.0283 & 0.0133 & 0.0263 & 0.0248 & 0.0311 \\
\hline
\end{tabular}




\section{Table 6}

Performance of Optimal Portfolios for Sets of Preferences $E_{1}, E_{2}, E_{3}$ and $E_{6}$

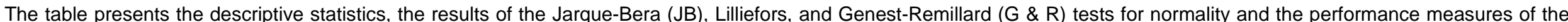

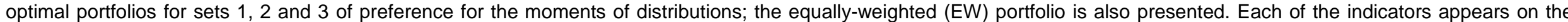

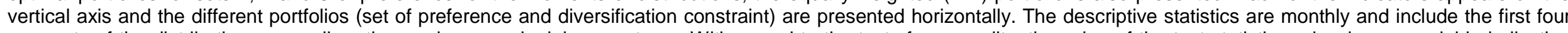

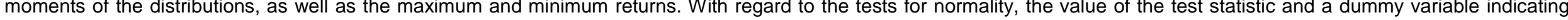

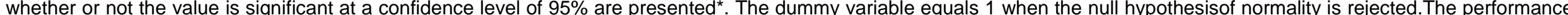

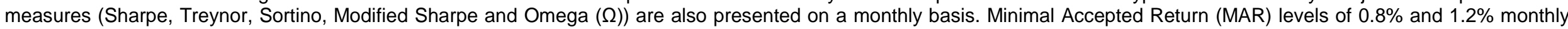

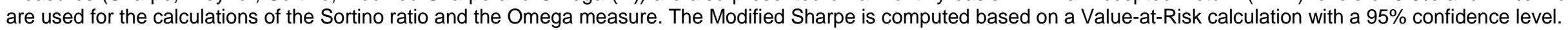

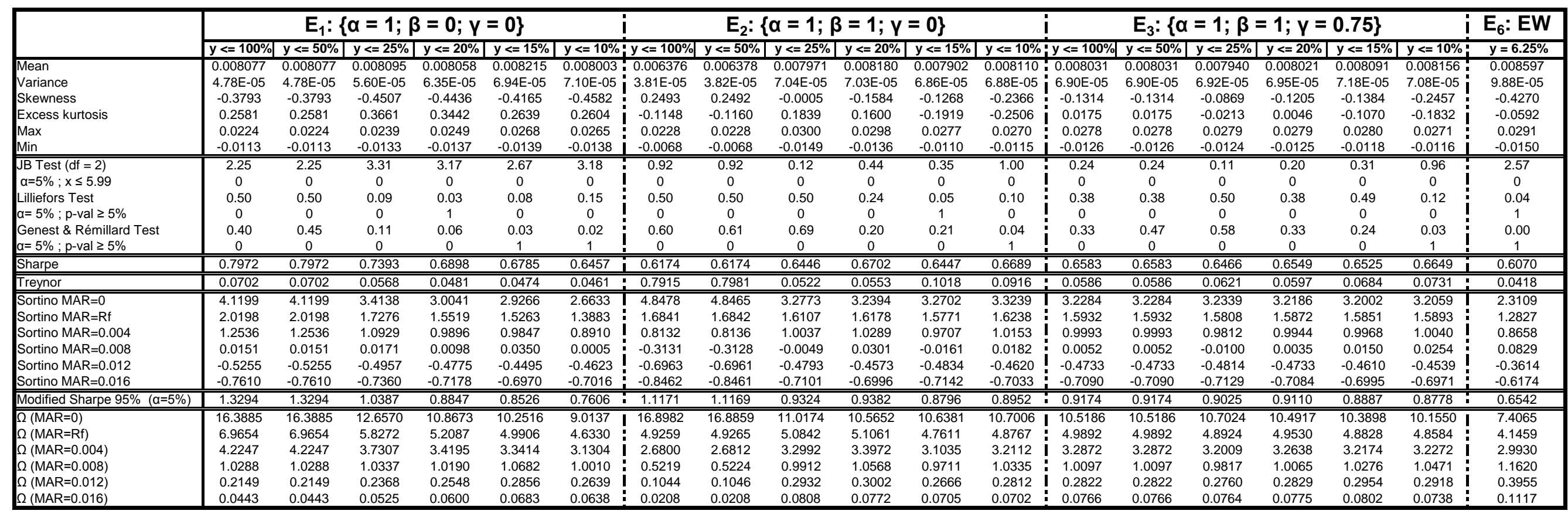

* P-values are available upon request. 


\section{Table 7}

\section{Performance and Rank of Portfolios According to the Comprehensive Measures}

The table shows the results, on a monthly basis, of the Sortino ratio, the Modified Sharpe ratio and the Omega measure $(\Omega)$ for all 30 optimal portfolios as well as the equally-weighted fund. The 31 portfolios and their characteristics (sets of preference and diversification constraint) appear on the vertical axis and the performance measures are presented horizontally. Minimal Accepted Return (MAR) levels of $0.8 \%$ and $1.2 \%$ monthly are used for the calculations of the Sortino ratio and the Omega measure. The Modified Sharpe was computed based on a Value-at-Risk calculation with a 95\% confidence level. To the right of each measure is the rank of the portfolio for a given indicator; 1 indicates the best performing portfolio and 31 , the worst performing one.

\begin{tabular}{|c|c|c|c|c|c|c|c|c|c|c|c|}
\hline$E_{h}$ & k & Sortino MAR $=0,008$ & Rank & Sortino $M A R=0,012$ & Rank & Modified Sharpe 95\% & Rank & $\Omega(\mathrm{MAR}=0,008)$ & Rank & $\Omega(\mathrm{MAR}=0,012)$ & Rank \\
\hline \multirow[t]{6}{*}{$E_{1}:\{\alpha=1 ; \beta=0 ; \gamma=0\}$} & $\mathrm{y} \leq 100 \%$ & 0.0151 & 12 & -0.5255 & 26 & 1.3294 & 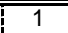 & 1.0288 & 12 & 0.2149 & 26 \\
\hline & $y \leq 50 \%$ & 0.0151 & 12 & -0.5255 & 26 & 1.3294 & 1 & 1.0288 & 12 & 0.2149 & 26 \\
\hline & $y \leq 25 \%$ & 0.0171 & 11 & -0.4957 & 25 & 1.0387 & 7 & 1.0337 & 10 & 0.2368 & 25 \\
\hline & $y \leq 20 \%$ & 0.0098 & 15 & -0.4775 & 21 & 0.8847 & 22 & 1.0190 & 15 & 0.2548 & 24 \\
\hline & $y \leq 15 \%$ & 0.0350 & 2 & -0.4495 & 4 & 0.8526 & 29 & 1.0682 & 2 & 0.2856 & 12 \\
\hline & $y \leq 10 \%$ & 0.0005 & 24 & -0.4623 & 12 & 0.7606 & 30 & 1.0010 & 24 & 0.2639 & 23 \\
\hline \multirow[t]{6}{*}{$E_{2}:\{\alpha=1 ; \beta=1 ; \gamma=0\}$} & $y \leq 100 \%$ & -0.3131 & 31 & -0.6963 & 31 & 1.1171 & 5 & 0.5219 & 31 & 0.1044 & 31 \\
\hline & $y \leq 50 \%$ & -0.3128 & 30 & -0.6961 & 30 & 1.1169 & 6 & 0.5224 & 30 & 0.1046 & 30 \\
\hline & $y \leq 25 \%$ & -0.0049 & 25 & -0.4793 & 22 & 0.9324 & 10 & 0.9912 & 25 & 0.2932 & 9 \\
\hline & $y \leq 20 \%$ & 0.0301 & 5 & -0.4573 & 9 & 0.9382 & 9 & 1.0568 & 5 & 0.3002 & 6 \\
\hline & $y \leq 15 \%$ & -0.0161 & 27 & -0.4834 & 24 & 0.8796 & 24 & 0.9711 & 27 & 0.2666 & 22 \\
\hline & $y \leq 10 \%$ & 0.0182 & 10 & -0.4620 & 11 & 0.8952 & 17 & 1.0335 & 11 & 0.2812 & 17 \\
\hline \multirow[t]{6}{*}{$E_{3}:\{\alpha=1 ; \beta=1 ; \gamma=0.75\}$} & $y \leq 100 \%$ & 0.0052 & 21 & -0.4733 & 19 & 0.9174 & 11 & 1.0097 & 21 & 0.2822 & 15 \\
\hline & $y \leq 50 \%$ & 0.0052 & 21 & -0.4733 & 19 & 0.9174 & 11 & 1.0097 & 21 & 0.2822 & 15 \\
\hline & $y \leq 25 \%$ & -0.0100 & 26 & -0.4814 & 23 & 0.9025 & 15 & 0.9817 & 26 & 0.2760 & 21 \\
\hline & $y \leq 20 \%$ & 0.0035 & 23 & -0.4733 & 18 & 0.9110 & 13 & 1.0065 & 23 & 0.2829 & 14 \\
\hline & $y \leq 15 \%$ & 0.0150 & 14 & -0.4610 & 10 & 0.8887 & 21 & 1.0276 & 14 & 0.2954 & 8 \\
\hline & $y \leq 10 \%$ & 0.0254 & 8 & -0.4539 & 7 & 0.8778 & 26 & 1.0471 & 8 & 0.2918 & 10 \\
\hline \multirow[t]{6}{*}{$E_{4}:\{\alpha=2 ; \beta=1 ; \gamma=0.75\}$} & $y \leq 100 \%$ & 0.0067 & 19 & -0.4711 & 15 & 0.8944 & 18 & 1.0126 & 19 & 0.2811 & 18 \\
\hline & $y \leq 50 \%$ & 0.0067 & 19 & -0.4711 & 15 & 0.8944 & 18 & 1.0126 & 19 & 0.2811 & 18 \\
\hline & $y \leq 25 \%$ & 0.0070 & 18 & -0.4722 & 17 & 0.9029 & 14 & 1.0133 & 18 & 0.2794 & 20 \\
\hline & $y \leq 20 \%$ & 0.0082 & 17 & -0.4691 & 13 & 0.8907 & 20 & 1.0153 & 17 & 0.2832 & 13 \\
\hline & $y \leq 15 \%$ & 0.0278 & 7 & -0.4514 & 5 & 0.8797 & 23 & 1.0520 & 7 & 0.3019 & 5 \\
\hline & $y \leq 10 \%$ & 0.0337 & 3 & -0.4449 & 2 & 0.8531 & 28 & 1.0632 & 3 & 0.2977 & 7 \\
\hline \multirow[t]{6}{*}{$E_{5}:\{a=3 ; \beta=1 ; \gamma=0.25\}$} & $y \leq 100 \%$ & -0.2761 & 29 & -0.6781 & 29 & 1.1416 & 4 & 0.5693 & 29 & 0.1170 & 29 \\
\hline & $y \leq 50 \%$ & -0.2754 & 28 & -0.6779 & 28 & 1.1439 & 3 & 0.5702 & 28 & 0.1172 & 28 \\
\hline & $y \leq 25 \%$ & 0.0087 & 16 & -0.4700 & 14 & 0.9402 & 8 & 1.0156 & 16 & 0.3046 & 3 \\
\hline & $y \leq 20 \%$ & 0.0293 & 6 & -0.4515 & 6 & 0.8965 & 16 & 1.0553 & 6 & 0.3097 & 2 \\
\hline & $y \leq 15 \%$ & 0.0318 & 4 & -0.4476 & 3 & 0.8680 & 27 & 1.0603 & 4 & 0.3038 & 4 \\
\hline & $y \leq 10 \%$ & 0.0236 & 9 & -0.4572 & 8 & 0.8780 & 25 & 1.0439 & 9 & 0.2864 & 11 \\
\hline $\mathrm{E}_{6}: \mathrm{EW}(\mathrm{1} / \mathrm{m})$ & $y=6.25 \%$ & 0.0829 & 1 & -0.3614 & 1 & 0.6542 & 31 & 1.1620 & 1 & 0.3955 & 1 \\
\hline
\end{tabular}


Table 8

Performance of CFOs 11, 15 and 18

Table 8 presents the descriptive statistics, the results of the Jarque-Bera (JB), Lilliefors, and Genest-Remillard (G \& R) tests for normality and the performance measures of CFO structures 11 (panel A), 15 (Panel B) and 18 (Panel C) constructed from the 31 hedge fund portfolios. For each of the three CFO structures, the nature of the underlying portfolio (set of preference and diversification constraint) appears on the vertical axis and their statistics within the particular CFO structure are presented horizontally. As a reference, the value of the debt portion of the CFO's $\$ 400 \mathrm{M}$ and the all-in funding cost, in basis points over the $1 \mathrm{M}$ LIBOR, appear at the top of each panel. The descriptive statistics are monthly and include the first four moments of the distributions, as well as the minimum and maximum returns. With regard to the tests for normality, the value of the test statistic and a dummy variable indicating whether or not the value is significant at a confidence level of $95 \%$ are presented*. The dummy variable equals 1 when the null hypothesis of normality is rejected. The performance measures (Sharpe, Treynor, Sortino, Modified Sharpe and Omega $(\Omega)$ ) are also presented on a monthly basis. For the Sortino ratio and the Omega measure, the calculations are made for Minimal Accepted Return (MAR) levels of $0.8 \%$ and $1.2 \%$ monthly. The Modified Sharpe is computed based on a VaR with a $95 \%$ confidence level.

PANEL A

\begin{tabular}{|c|c|c|c|c|c|c|c|c|c|c|c|c|c|c|c|}
\hline \multirow[b]{2}{*}{$E_{h}$} & \multirow[b]{2}{*}{ k } & \multicolumn{14}{|c|}{ CFO 11 (Debt $=\$ 200 \mathrm{M} ;$ All-in funding cost $=150$ bps over LIBOR 1 month) } \\
\hline & & Mean & Variance & Skewness & $\begin{array}{l}\text { Excess } \\
\text { kurtosis }\end{array}$ & $\begin{array}{c}J B \\
\alpha=5 \%\end{array}$ & $\begin{array}{c}\text { Lilliefors } \\
\alpha=5 \%\end{array}$ & $\begin{array}{c}G \& R \\
\alpha=5 \%\end{array}$ & Sharpe & Treynor & $\begin{array}{c}\text { Sortino } \\
\text { MAR }=0.008\end{array}$ & $\begin{array}{c}\text { Sortino } \\
\text { MAR }=0.012\end{array}$ & $\begin{array}{c}\text { Modified } \\
\text { Sharpe } \\
\alpha=5 \%\end{array}$ & $\begin{array}{c}\Omega \\
\text { MAR }=0.008\end{array}$ & $\begin{array}{c}\Omega \\
\text { MAR }=0.012\end{array}$ \\
\hline \multirow{6}{*}{$\bar{E} E_{1}:\{\alpha=1 ; \beta=0 ; \gamma=0\}$} & $\mathrm{y} \leq 100 \%$ & $=0.0098$ & $\begin{array}{l}1.255 \mathrm{E}-04 \\
\end{array}$ & 作 & 年-0.0136 & 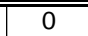 & $\overline{00}$ & $\overline{00}$ & 些0.6472 & "0.0602 & "0.9963 & (0.769 & 然.7509 & $\bar{~}$ & $\begin{array}{c}0.6018 \\
\end{array}$ \\
\hline & $y \leq 50 \%$ & 0.0098 & $1.255 \mathrm{E}-04$ & -0.2858 & -0.0136 & 0 & 0 & 0 & 0.6472 & 0.0602 & 0.9963 & 0.769 & 0.7509 & 1.5024 & 0.6018 \\
\hline & $y \leq 25 \%$ & 0.0098 & 1.460E-04 & -0.4064 & 0.0752 & 0 & 0 & 0 & 0.6017 & 0.0473 & 0.8977 & 0.713 & 0.6216 & 1.4668 & 0.6245 \\
\hline & $y \leq 20 \%$ & 0.0098 & 1.667E-04 & -0.4104 & 0.0762 & 0 & 0 & 0 & 0.5586 & 0.0391 & 0.8231 & 0.6628 & 0.5444 & 1.4090 & 0.6377 \\
\hline & $y \leq 15 \%$ & 0.0100 & $1.817 \mathrm{E}-04$ & -0.4135 & -0.0191 & 0 & 0 & 1 & 0.5524 & 0.0388 & 0.8173 & 0.6635 & 0.5292 & 1.4435 & 0.6826 \\
\hline & $y \leq 10 \%$ & 0.0097 & 1.861E-04 & -0.4443 & -0.0123 & 0 & 1 & 1 & 0.5225 & 0.0377 & 0.7553 & 0.6162 & 0.4802 & 1.3567 & 0.6439 \\
\hline \multirow[t]{6}{*}{$E_{2}:\{\alpha=1 ; \beta=1 ; \gamma=0\}$} & $y \leq 100 \%$ & 0.0071 & 1.157E-04 & 0.4734 & 0.2580 & 0 & 0 & 0 & 0.4201 & -0.5235 & 0.5943 & 0.4390 & 0.4786 & 0.8059 & 0.3329 \\
\hline & $y \leq 50 \%$ & 0.0071 & $1.158 \mathrm{E}-04$ & 0.4729 & 0.2559 & 0 & 0 & 0 & 0.4202 & -0.5181 & 0.5946 & 0.4393 & 0.4788 & 0.8064 & 0.3333 \\
\hline & $y \leq 25 \%$ & 0.0096 & $1.858 \mathrm{E}-04$ & 0.0043 & -0.2065 & 0 & 0 & 0 & 0.5179 & 0.0428 & 0.8107 & 0.6420 & 0.5497 & 1.3531 & 0.6461 \\
\hline & $y \leq 20 \%$ & 0.0100 & 1.817E-04 & -0.1852 & -0.2746 & 0 & 0 & 0 & 0.5482 & 0.0467 & 0.8407 & 0.6739 & 0.5654 & 1.4338 & 0.6780 \\
\hline & $y \leq 15 \%$ & 0.0095 & $1.808 \mathrm{E}-04$ & -0.1361 & -0.4612 & 0 & 1 & 0 & 0.5194 & 0.1051 & 0.7842 & 0.6247 & 0.5270 & 1.3207 & 0.6303 \\
\hline & $y \leq 10 \%$ & 0.0099 & 1.794E-04 & -0.2355 & -0.5394 & 0 & 0 & 1 & 0.5460 & 0.0909 & 0.8255 & 0.6596 & 0.5498 & 1.3960 & 0.6706 \\
\hline \multirow[t]{6}{*}{$E_{3}:\{\alpha=1 ; \beta=1 ; \gamma=0.75\}$} & $y \leq 100 \%$ & 0.0097 & 1.790E-04 & -0.1204 & -0.2906 & 0 & 0 & 0 & 0.5359 & 0.0497 & 0.8216 & 0.6545 & 0.5585 & 1.3785 & 0.6504 \\
\hline & $y \leq 50 \%$ & 0.0097 & $1.790 \mathrm{E}-04$ & -0.1204 & -0.2906 & 0 & 0 & 0 & 0.5359 & 0.0497 & 0.8216 & 0.6545 & 0.5585 & 1.3785 & 0.6504 \\
\hline & $y \leq 25 \%$ & 0.0096 & 1.803E-04 & -0.0757 & -0.3115 & 0 & 0 & 0 & 0.5236 & 0.0531 & 0.8019 & 0.6374 & 0.5459 & 1.3396 & 0.6350 \\
\hline & $y \leq 20 \%$ & 0.0097 & 1.803E-04 & -0.1110 & -0.3004 & 0 & 0 & 0 & 0.5329 & 0.0508 & 0.8170 & 0.6509 & 0.5547 & 1.3718 & 0.6497 \\
\hline & $y \leq 15 \%$ & 0.0098 & 1.864E-04 & -0.1286 & -0.3860 & 0 & 0 & 0 & 0.5326 & 0.0609 & 0.8170 & 0.6528 & 0.5483 & 1.3868 & 0.6698 \\
\hline & $y \leq 10 \%$ & 0.0099 & $1.835 \mathrm{E}-04$ & -0.2351 & -0.4667 & 0 & 1 & 1 & 0.5448 & 0.0668 & 0.8258 & 0.6615 & 0.5476 & 1.4111 & 0.6826 \\
\hline \multirow[t]{6}{*}{$E_{4}:\{\alpha=2 ; \beta=1 ; \gamma=0.75\}$} & $y \leq 100 \%$ & 0.0097 & 1.791E-04 & -0.1920 & -0.1883 & 0 & 0 & 0 & 0.5366 & 0.0422 & 0.8139 & 0.6516 & 0.5473 & 1.3829 & 0.6489 \\
\hline & $y \leq 50 \%$ & 0.0097 & 1.791E-04 & -0.1920 & -0.1883 & 0 & 0 & 0 & 0.5366 & 0.0422 & 0.8139 & 0.6516 & 0.5473 & 1.3829 & 0.6489 \\
\hline & $y \leq 25 \%$ & 0.0097 & $1.775 \mathrm{E}-04$ & -0.1939 & -0.1886 & 0 & 0 & 0 & 0.5393 & 0.0429 & 0.8185 & 0.6546 & 0.5517 & 1.3858 & 0.6481 \\
\hline & $y \leq 20 \%$ & 0.0098 & 1.803E-04 & -0.1847 & -0.2076 & 0 & 0 & 0 & 0.5360 & 0.0431 & 0.8145 & 0.6519 & 0.5473 & 1.3840 & 0.6521 \\
\hline & $y \leq 15 \%$ & 0.0100 & 1.870E-04 & -0.1854 & -0.3037 & 0 & 0 & 0 & 0.5406 & 0.0491 & 0.8283 & 0.6635 & 0.5513 & 1.4187 & 0.6849 \\
\hline & $y \leq 10 \%$ & 0.0100 & 1.864E-04 & -0.2818 & -0.3614 & 0 & 1 & 1 & 0.5463 & 0.0531 & 0.8258 & 0.6639 & 0.5412 & 1.4294 & 0.6959 \\
\hline \multirow{6}{*}{$E_{5}:\{\alpha=3 ; \beta=1 ; \gamma=0.25\}$} & $y \leq 100 \%$ & 0.0074 & 1.159E-04 & 0.3280 & -0.0388 & 0 & 0 & 0 & 0.4488 & 0.2628 & 0.6398 & 0.4747 & 0.5098 & 0.8689 & 0.3538 \\
\hline & $y \leq 50 \%$ & 0.0074 & 1.159E-04 & 0.3277 & -0.0381 & 0 & 0 & 0 & 0.4496 & 0.2637 & 0.6412 & 0.4757 & 0.5111 & 0.8704 & 0.3543 \\
\hline & $y \leq 25 \%$ & 0.0097 & 1.890E-04 & 0.0167 & -0.1873 & 0 & 0 & 0 & 0.5225 & 0.0403 & 0.8251 & 0.6536 & 0.5587 & 1.3806 & 0.6639 \\
\hline & $y \leq 20 \%$ & 0.0100 & 1.899E-04 & -0.1505 & -0.2202 & 0 & 0 & 0 & 0.5364 & 0.0404 & 0.8271 & 0.6637 & 0.5512 & 1.4256 & 0.6860 \\
\hline & $y \leq 15 \%$ & 0.0100 & 1.872E-04 & -0.2307 & -0.2506 & 0 & 0 & 0 & 0.5430 & 0.0456 & 0.8271 & 0.6650 & 0.5470 & 1.4285 & 0.6887 \\
\hline & $y \leq 10 \%$ & 0.0099 & 1.795E-04 & -0.2604 & -0.3925 & 0 & 1 & 1 & 0.5497 & 0.0705 & 0.8313 & 0.6654 & 0.5522 & 1.4137 & 0.6768 \\
\hline $\mathrm{E}_{6}: \mathrm{EW}(\mathrm{i} / \mathrm{m})$ & $y=6.25 \%$ & 0.0106 & $2.565 \mathrm{E}-04$ & -0.3987 & -0.1921 & 0 & 1 & 1 & 0.5033 & 0.0345 & 0.7522 & 0.6283 & 0.4491 & 1.4854 & 0.8058 \\
\hline
\end{tabular}




\section{Table 8}

Performance of CFOs 11, 15 and 18 (continued)

\section{PANEL B}

\begin{tabular}{|c|c|c|c|c|c|c|c|c|c|c|c|c|c|c|c|}
\hline \multirow[b]{2}{*}{$E_{h}$} & \multirow[b]{2}{*}{ k } & \multicolumn{14}{|c|}{ CFO 15 (Debt = \$280 M ; All-in funding cost = 200 bps over LIBOR 1 month) } \\
\hline & & Mean & Variance & Skewness & $\begin{array}{l}\text { Excess } \\
\text { kurtosis }\end{array}$ & $\begin{array}{c}J B \\
\alpha=5 \%\end{array}$ & $\begin{array}{c}\text { Lilliefors } \\
\alpha=5 \%\end{array}$ & $\begin{array}{c}\text { G\&R } \\
\alpha=5 \%\end{array}$ & Sharpe & Treynor & $\begin{array}{c}\text { Sortino } \\
\text { MAR }=0.008\end{array}$ & $\begin{array}{c}\text { Sortino } \\
\text { MAR }=0.012\end{array}$ & $\begin{array}{c}\text { Modified } \\
\text { Sharpe } \\
\alpha=5 \%\end{array}$ & $\begin{array}{c}\Omega \\
\text { MAR=0.008 }\end{array}$ & $\begin{array}{c}\Omega \\
\text { MAR }=0.012\end{array}$ \\
\hline \multirow[t]{6}{*}{$E_{1}:\{\alpha=1 ; \beta=0 ; \gamma=0\}$} & $y \leq 100 \%$ & 0.0120 & $2.540 \mathrm{E}-04$ & -0.1768 & -0.0826 & 0 & 0 & 0 & 0.5936 & 0.0568 & 0.9984 & 0.8212 & 0.6269 & 1.8739 & 1.0037 \\
\hline & $y \leq 50 \%$ & 0.0120 & $2.540 \mathrm{E}-04$ & -0.1768 & -0.0826 & 0 & 0 & 0 & 0.5936 & 0.0568 & 0.9984 & 0.8212 & 0.6269 & 1.8739 & 1.0037 \\
\hline & $y \leq 25 \%$ & 0.0120 & 2.953E-04 & -0.3433 & 0.0178 & 0 & 0 & 0 & 0.5520 & 0.0435 & 0.8855 & 0.7464 & 0.5221 & 1.7975 & 1.0072 \\
\hline & $y \leq 20 \%$ & 0.0120 & 3.400E-04 & -0.3646 & 0.0435 & 0 & 0 & 0 & 0.5104 & 0.0354 & 0.8034 & 0.6847 & 0.4571 & 1.6978 & 0.9963 \\
\hline & $y \leq 15 \%$ & 0.0123 & 3.710E-04 & -0.3883 & -0.0460 & 0 & 1 & 1 & 0.5047 & 0.0351 & 0.7930 & 0.6801 & 0.4430 & 1.7162 & 1.0374 \\
\hline & $y \leq 10 \%$ & 0.0119 & 3.789E-04 & -0.4098 & -0.0714 & 0 & 1 & 1 & 0.4779 & 0.0342 & 0.7347 & 0.6319 & 0.4063 & 1.6207 & 0.9830 \\
\hline \multirow[t]{6}{*}{$E_{2}:\{\alpha=1 ; \beta=1 ; \gamma=0\}$} & $y \leq 100 \%$ & 0.0082 & 2.646E-04 & 0.6583 & 0.6494 & 1 & 0 & 0 & 0.3473 & -0.2364 & 0.5518 & 0.4412 & 0.3476 & 1.0343 & 0.5617 \\
\hline & $y \leq 50 \%$ & 0.0082 & $2.647 \mathrm{E}-04$ & 0.6577 & 0.6468 & 1 & 0 & 1 & 0.3475 & -0.2350 & 0.5522 & 0.4416 & 0.3478 & 1.0349 & 0.5621 \\
\hline & $y \leq 25 \%$ & 0.0118 & 3.824E-04 & 0.0606 & -0.3049 & 0 & 0 & 0 & 0.4703 & 0.0390 & 0.7901 & 0.6657 & 0.4552 & 1.6278 & 0.9696 \\
\hline & $y \leq 20 \%$ & 0.0122 & 3.666E-04 & -0.1560 & -0.4277 & 0 & 0 & 0 & 0.5035 & 0.0431 & 0.8248 & 0.6991 & 0.4732 & 1.7107 & 1.0270 \\
\hline & $y \leq 15 \%$ & 0.0117 & 3.664E-04 & -0.0863 & -0.5361 & 0 & 1 & 1 & 0.4762 & 0.1154 & 0.7742 & 0.6517 & 0.4446 & 1.5821 & 0.9598 \\
\hline & $y \leq 10 \%$ & 0.0121 & 3.595E-04 & -0.1839 & -0.6645 & 0 & 1 & 1 & 0.5042 & 0.0957 & 0.8214 & 0.6914 & 0.4686 & 1.6662 & 1.0157 \\
\hline \multirow[t]{6}{*}{$E_{3}:\{\alpha=1 ; \beta=1 ; \gamma=0.75\}$} & $y \leq 100 \%$ & 0.0119 & 3.594E-04 & -0.0623 & -0.4081 & 0 & 0 & 0 & 0.4935 & 0.0466 & 0.8147 & 0.6855 & 0.4733 & 1.6559 & 0.9894 \\
\hline & $y \leq 50 \%$ & 0.0119 & 3.594E-04 & -0.0623 & -0.4081 & 0 & 0 & 0 & 0.4935 & 0.0466 & 0.8147 & 0.6855 & 0.4733 & 1.6559 & 0.9894 \\
\hline & $y \leq 25 \%$ & 0.0117 & 3.626E-04 & -0.0169 & -0.4277 & 0 & 0 & 0 & 0.4814 & 0.0503 & 0.7952 & 0.6676 & 0.4617 & 1.6103 & 0.9655 \\
\hline & $y \leq 20 \%$ & 0.0119 & 3.620E-04 & -0.0530 & -0.4179 & 0 & 0 & 0 & 0.4907 & 0.0479 & 0.8103 & 0.6816 & 0.4702 & 1.6481 & 0.9868 \\
\hline & $y \leq 15 \%$ & 0.0121 & 3.736E-04 & -0.0663 & -0.4851 & 0 & 0 & 0 & 0.4914 & 0.0593 & 0.8123 & 0.6841 & 0.4679 & 1.6557 & 1.0078 \\
\hline & $y \leq 10 \%$ & 0.0122 & 3.663E-04 & -0.1794 & -0.5968 & 0 & 1 & 1 & 0.5041 & 0.0660 & 0.8225 & 0.6942 & 0.4691 & 1.6829 & 1.0269 \\
\hline \multirow[t]{6}{*}{$\mathrm{E}_{4}:\{\alpha=2 ; \beta=1 ; \gamma=0.75\}$} & $y \leq 100 \%$ & 0.0119 & 3.607E-04 & -0.1434 & -0.3167 & 0 & 0 & 0 & 0.4932 & 0.0387 & 0.8023 & 0.6786 & 0.4623 & 1.6623 & 0.9907 \\
\hline & $y \leq 50 \%$ & 0.0119 & 3.607E-04 & -0.1434 & -0.3167 & 0 & 0 & 0 & 0.4932 & 0.0387 & 0.8023 & 0.6786 & 0.4623 & 1.6623 & 0.9907 \\
\hline & $y \leq 25 \%$ & 0.0119 & 3.570E-04 & -0.1445 & -0.3204 & 0 & 0 & 0 & 0.4959 & 0.0394 & 0.8078 & 0.6825 & 0.4662 & 1.6675 & 0.9913 \\
\hline & $y \leq 20 \%$ & 0.0120 & 3.624E-04 & -0.1323 & -0.3354 & 0 & 0 & 0 & 0.4932 & 0.0396 & 0.8045 & 0.6799 & 0.4636 & 1.6622 & 0.9938 \\
\hline & $y \leq 15 \%$ & 0.0122 & 3.729E-04 & -0.1244 & -0.4274 & 0 & 0 & 0 & 0.5001 & 0.0462 & 0.8244 & 0.6962 & 0.4725 & 1.6962 & 1.0282 \\
\hline & $y \leq 10 \%$ & 0.0123 & 3.709E-04 & -0.2267 & -0.4916 & 0 & 1 & 1 & 0.5063 & 0.0506 & 0.8229 & 0.6968 & 0.4658 & 1.7089 & 1.0403 \\
\hline \multirow[t]{6}{*}{$E_{5}:\{\alpha=3 ; \beta=1 ; \gamma=0.25\}$} & $y \leq 100 \%$ & 0.0087 & $2.595 \mathrm{E}-04$ & 0.4900 & 0.2461 & 0 & 0 & 0 & 0.3784 & 0.3634 & 0.6023 & 0.4826 & 0.3799 & 1.1096 & 0.5994 \\
\hline & $y \leq 50 \%$ & 0.0087 & 2.594E-04 & 0.4902 & 0.2475 & 0 & 0 & 0 & 0.3792 & 0.3658 & 0.6039 & 0.4838 & 0.3810 & 1.1115 & 0.6002 \\
\hline & $y \leq 25 \%$ & 0.0119 & 3.888E-04 & 0.0769 & -0.2680 & 0 & 0 & 0 & 0.4750 & 0.0365 & 0.8048 & 0.6781 & 0.4637 & 1.6552 & 0.9910 \\
\hline & $y \leq 20 \%$ & 0.0122 & 3.844E-04 & -0.1036 & -0.3333 & 0 & 0 & 0 & 0.4922 & 0.0369 & 0.8116 & 0.6889 & 0.4644 & 1.7013 & 1.0274 \\
\hline & $y \leq 15 \%$ & 0.0123 & 3.732E-04 & -0.1756 & -0.3896 & 0 & 0 & 0 & 0.5025 & 0.0425 & 0.8217 & 0.6959 & 0.4688 & 1.7050 & 1.0348 \\
\hline & $y \leq 10 \%$ & 0.0122 & 3.569E-04 & -0.1913 & -0.5283 & 0 & 1 & 1 & 0.5097 & 0.0705 & 0.8319 & 0.7010 & 0.4765 & 1.6917 & 1.0250 \\
\hline $\mathrm{E}_{6}: \mathrm{EW}(1 / \mathrm{m})$ & $y=6.25 \%$ & 0.0131 & 5.175E-04 & -0.3569 & -0.1135 & 0 & 1 & 1 & 0.4648 & 0.0315 & 0.7350 & 0.6429 & 0.3909 & 1.7174 & 1.1298 \\
\hline
\end{tabular}


Table 8

Performance of CFOs 11, 15 and 18 (continued)

PANEL C

\begin{tabular}{|c|c|c|c|c|c|c|c|c|c|c|c|c|c|c|c|}
\hline \multirow[b]{2}{*}{$E_{h}$} & \multirow[b]{2}{*}{ k } & \multicolumn{14}{|c|}{ CFO 18 (Debt $=\$ 340 \mathrm{M} ;$ All-in funding cost $=300 \mathrm{bps}$ over LIBOR 1 month) } \\
\hline & & Mean & Variance & Skewness & $\begin{array}{l}\text { Excess } \\
\text { kurtosis }\end{array}$ & $\begin{array}{c}J B \\
\alpha=5 \%\end{array}$ & $\begin{array}{c}\text { Lilliefors } \\
\alpha=5 \%\end{array}$ & $\begin{array}{r}G \& R \\
\alpha=5 \%\end{array}$ & Sharpe & Treynor & $\begin{array}{c}\text { Sortino } \\
\text { MAR }=0.008\end{array}$ & $\begin{array}{c}\text { Sortino } \\
\text { MAR }=0.012\end{array}$ & $\begin{array}{c}\text { Modified } \\
\text { Sharpe } \\
\alpha=5 \%\end{array}$ & $\begin{array}{c}\Omega \\
\text { MAR }=0.008\end{array}$ & $\begin{array}{c}\Omega \\
\text { MAR }=0.012\end{array}$ \\
\hline \multirow[t]{6}{*}{$E_{1}:\{\alpha=1 ; \beta=0 ; \gamma=0\}$} & $y \leq 100 \%$ & 0.0149 & $\begin{array}{l}6.779 \mathrm{E}-04 \\
\end{array}$ & "-0.0187 & 然.0959 & 0 & 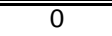 & 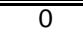 & "0.4749 & 0.0474 & "0.8314 & "0.7326 & 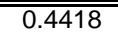 & "1.9585 & 1.3345 \\
\hline & $y \leq 50 \%$ & 0.0149 & 6.779E-04 & -0.0187 & 0.0959 & 0 & 0 & 0 & 0.4749 & 0.0474 & 0.8314 & 0.7326 & 0.4418 & 1.9585 & 1.3345 \\
\hline & $y \leq 25 \%$ & 0.015 & 7.978E-04 & -0.2632 & 0.2770 & 0 & 0 & 0 & 0.4394 & 0.0348 & 0.7237 & 0.6497 & 0.3682 & 1.8608 & 1.3082 \\
\hline & $y \leq 20 \%$ & 0.0149 & $9.408 \mathrm{E}-04$ & -0.3193 & 0.3499 & 0 & 0 & 0 & 0.4018 & 0.0276 & 0.6445 & 0.5839 & 0.3196 & 1.7455 & 1.2680 \\
\hline & $y \leq 15 \%$ & 0.0154 & 1.038E-03 & -0.3688 & 0.3002 & 0 & 0 & 0 & 0.3974 & 0.0275 & 0.6325 & 0.5759 & 0.3092 & 1.7514 & 1.2960 \\
\hline & $y \leq 10 \%$ & 0.0147 & 1.047E-03 & -0.3740 & 0.1657 & 0 & 1 & 0 & 0.3764 & 0.0267 & 0.5891 & 0.5366 & 0.2870 & 1.6642 & 1.2325 \\
\hline \multirow[t]{6}{*}{$E_{2}:\{\alpha=1 ; \beta=1 ; \gamma=0\}$} & $y \leq 100 \%$ & 0.0087 & 8.573E-04 & 0.8688 & 1.2782 & 1 & 1 & 1 & 0.2080 & -0.0990 & 0.3433 & 0.3004 & 0.1762 & 1.0600 & 0.7474 \\
\hline & $y \leq 50 \%$ & 0.0087 & 8.573E-04 & 0.8682 & 1.2748 & 1 & 1 & 1 & 0.2082 & -0.0986 & 0.3438 & 0.3008 & 0.1764 & 1.0607 & 0.7479 \\
\hline & $y \leq 25 \%$ & 0.0146 & 1.092E-03 & 0.1824 & -0.0811 & 0 & 0 & 0 & 0.3632 & 0.0306 & 0.6259 & 0.5633 & 0.3135 & 1.6629 & 1.2187 \\
\hline & $y \leq 20 \%$ & 0.0152 & 1.004E-03 & -0.0837 & -0.3054 & 0 & 0 & 0 & 0.3996 & 0.0347 & 0.6682 & 0.6024 & 0.3343 & 1.7538 & 1.2895 \\
\hline & $y \leq 15 \%$ & 0.0145 & 9.800E-04 & 0.0330 & -0.4012 & 0 & 0 & 0 & 0.3799 & 0.1286 & 0.6379 & 0.5707 & 0.3214 & 1.6425 & 1.2108 \\
\hline & $y \leq 10 \%$ & 0.0151 & $9.415 \mathrm{E}-04$ & -0.0809 & -0.6626 & 0 & 1 & 1 & 0.4096 & 0.0978 & 0.6893 & 0.6157 & 0.3444 & 1.7311 & 1.2769 \\
\hline \multirow[t]{6}{*}{$E_{3}:\{\alpha=1 ; \beta=1 ; \gamma=0.75\}$} & $y \leq 100 \%$ & 0.0148 & $9.627 \mathrm{E}-04$ & 0.0564 & -0.3723 & 0 & 0 & 0 & 0.3943 & 0.0385 & 0.6726 & 0.6013 & 0.3400 & 1.7103 & 1.2484 \\
\hline & $y \leq 50 \%$ & 0.0148 & 9.627E-04 & 0.0564 & -0.3723 & 0 & 0 & 0 & 0.3943 & 0.0385 & 0.6726 & 0.6013 & 0.3400 & 1.7103 & 1.2484 \\
\hline & $y \leq 25 \%$ & 0.0145 & $9.726 \mathrm{E}-04$ & 0.1058 & -0.4254 & 0 & 0 & 0 & 0.3832 & 0.0421 & 0.6553 & 0.5846 & 0.3304 & 1.6637 & 1.2176 \\
\hline & $y \leq 20 \%$ & 0.0148 & 9.691E-04 & 0.0682 & -0.3887 & 0 & 0 & 0 & 0.3921 & 0.0397 & 0.6693 & 0.5981 & 0.3381 & 1.7027 & 1.2436 \\
\hline & $y \leq 15 \%$ & 0.0150 & 9.911E-04 & 0.0678 & -0.4240 & 0 & 0 & 1 & 0.3960 & 0.0523 & 0.6781 & 0.6059 & 0.3421 & 1.7125 & 1.2634 \\
\hline & $y \leq 10 \%$ & 0.0153 & 9.583E-04 & -0.0742 & -0.6260 & 0 & 0 & 0 & 0.4101 & 0.0600 & 0.6915 & 0.6187 & 0.3456 & 1.7465 & 1.2889 \\
\hline \multirow{6}{*}{$E_{4}:\{\alpha=2 ; \beta=1 ; \gamma=0.75\}$} & $y \leq 100 \%$ & 0.0148 & 9.786E-04 & -0.0544 & -0.2381 & 0 & 0 & 0 & 0.3916 & 0.0307 & 0.6538 & 0.5876 & 0.3285 & 1.7100 & 1.2484 \\
\hline & $y \leq 50 \%$ & 0.0148 & $9.786 \mathrm{E}-04$ & -0.0544 & -0.2381 & 0 & 0 & 0 & 0.3916 & 0.0307 & 0.6538 & 0.5876 & 0.3285 & 1.7100 & 1.2484 \\
\hline & $y \leq 25 \%$ & 0.0148 & 9.663E-04 & -0.0537 & -0.2516 & 0 & 0 & 0 & 0.3943 & 0.0313 & 0.6595 & 0.5922 & 0.3316 & 1.7162 & 1.2506 \\
\hline & $y \leq 20 \%$ & 0.0149 & 9.791E-04 & -0.0351 & -0.2727 & 0 & 0 & 0 & 0.3927 & 0.0316 & 0.6586 & 0.5912 & 0.3311 & 1.7112 & 1.2508 \\
\hline & $y \leq 15 \%$ & 0.0153 & $9.873 \mathrm{E}-04$ & -0.0033 & -0.3939 & 0 & 1 & 0 & 0.4042 & 0.0385 & 0.6891 & 0.6171 & 0.3461 & 1.7537 & 1.2874 \\
\hline & $y \leq 10 \%$ & 0.0154 & $9.708 \mathrm{E}-04$ & -0.1297 & -0.5004 & 0 & 0 & 0 & 0.4125 & 0.0432 & 0.6923 & 0.6210 & 0.3439 & 1.7710 & 1.3017 \\
\hline \multirow[t]{7}{*}{$E_{5}:\{\alpha=3 ; \beta=1 ; Y=0.25\}$} & $y \leq 100 \%$ & 0.0094 & 8.231E-04 & 0.7112 & 0.8357 & 1 & 0 & 0 & 0.2395 & 0.7232 & 0.3967 & 0.3468 & 0.2053 & 1.1371 & 0.7980 \\
\hline & $y \leq 50 \%$ & 0.0095 & 8.222E-04 & 0.7120 & 0.8381 & 1 & 0 & 0 & 0.2403 & 0.7433 & 0.3984 & 0.3482 & 0.2061 & 1.1393 & 0.7993 \\
\hline & $y \leq 25 \%$ & 0.0148 & 1.111E-03 & 0.1996 & -0.0070 & 0 & 0 & 0 & 0.3680 & 0.0284 & 0.6386 & 0.5749 & 0.3203 & 1.6894 & 1.2410 \\
\hline & $y \leq 20 \%$ & 0.0153 & 1.059E-03 & -0.0150 & -0.1675 & 0 & 0 & 0 & 0.3901 & 0.0292 & 0.6576 & 0.5935 & 0.3295 & 1.7425 & 1.2836 \\
\hline & $y \leq 15 \%$ & 0.0153 & 9.901E-04 & -0.0701 & -0.3556 & 0 & 0 & 0 & 0.4061 & 0.0349 & 0.6845 & 0.6145 & 0.3426 & 1.7594 & 1.2945 \\
\hline & $y \leq 10 \%$ & 0.0152 & $9.250 \mathrm{E}-04$ & -0.0578 & -0.5521 & 0 & 0 & 1 & 0.4165 & 0.0654 & 0.7057 & 0.6298 & 0.3553 & 1.7602 & 1.2916 \\
\hline & $y=6.25 \%$ & 0.0167 & 1.412E-03 & -0.3207 & 0.3804 & 0 & 0 & 0 & 0.3771 & 0.0255 & 0.6070 & 0.5588 & 0.2906 & 1.7599 & 1.3623 \\
\hline
\end{tabular}

* P-values are available upon request. 


\section{Table 9}

\section{Results of Multivariate Linear Regressions for CFOs 1, 11, 15 and 18}

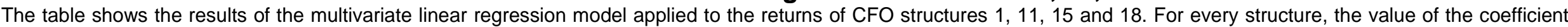

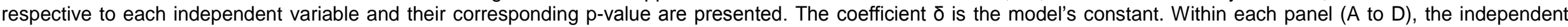

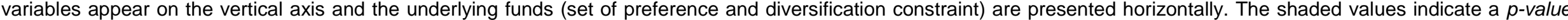
below $5 \%$.

\begin{tabular}{|c|c|c|c|c|c|c|c|}
\hline & \multicolumn{7}{|c|}{ CFO 1 (Direct exposure to Portfolio of HF) } \\
\hline & \multicolumn{7}{|c|}{ coefficients } \\
\hline & $\begin{array}{c}\{\alpha=1 ; \beta=0 ; \gamma=0\} \\
y \leq 100 \%\end{array}$ & $\begin{array}{c}\{\alpha=1 ; \beta=1 ; \gamma=0\} \\
y \leq 100 \%\end{array}$ & $\begin{array}{c}\{\alpha=1 ; \beta=1 ; \gamma=0\} \\
y \leq 20 \%\end{array}$ & $\begin{array}{c}\{\alpha=2 ; \beta=1 ; \gamma=0.75\} \\
y \leq 10 \%\end{array}$ & $\begin{array}{c}\{a=3 ; \beta=1 ; y=0.25\} \\
y \leq 50 \%\end{array}$ & $\begin{array}{c}\{\alpha=3 ; \beta=1 ; \gamma=0.25\} \\
y \leq 15 \%\end{array}$ & $\begin{array}{c}1 / \mathrm{m} \\
y=6.25 \%\end{array}$ \\
\hline $\begin{array}{l} \\
\text { STOCK } \\
\text { DEF } \\
\text { LIQU } \\
\text { TERM } \\
\text { TREND } \\
\end{array}$ & $\begin{array}{l}0.025818 \\
0.061247 \\
-0.000675 \\
-21.324371 \\
-2.305055 \\
-0.000144 \\
\end{array}$ & $\begin{array}{c}0.021177 \\
-0.008493 \\
-0.000480 \\
-20.243579 \\
-2.320236 \\
-0.000127 \\
\end{array}$ & $\begin{array}{c}0.024543 \\
0.082277 \\
-0.000671 \\
-11.967612 \\
-2.013981 \\
-0.000122 \\
\end{array}$ & $\begin{array}{c}0.025677 \\
0.077032 \\
-0.000603 \\
-21.047440 \\
-2.712104 \\
-0.000143 \\
\end{array}$ & $\begin{array}{c}.020373 \\
0.006984 \\
-0.000451 \\
-20.423683 \\
-2.214730 \\
-0.000116 \\
\end{array}$ & $\begin{array}{c}0.026133 \\
0.087423 \\
-0.000659 \\
-17.897796 \\
-2.580198 \\
-0.000142 \\
\end{array}$ & \begin{tabular}{|l|}
0.026712 \\
0.129787 \\
-0.000639 \\
-16.064178 \\
-2.646475 \\
-0.000151 \\
\end{tabular} \\
\hline & \multicolumn{7}{|c|}{ p-values } \\
\hline & $\begin{array}{c}\{\alpha=1 ; \beta=0 ; \gamma=0\} \\
y \leq 100 \%\end{array}$ & $\begin{array}{c}\{\alpha=1 ; \beta=1 ; \gamma=0\} \\
y \leq 100 \%\end{array}$ & $\begin{array}{c}\{\alpha=1 ; \beta=1 ; \gamma=0\} \\
y \leq 20 \%\end{array}$ & $\begin{array}{c}\{\alpha=2 ; \beta=1 ; \gamma=0.75\} \\
y \leq 10 \%\end{array}$ & $\begin{array}{c}\{\alpha=3 ; \beta=1 ; y=0.25\} \\
y \leq 50 \%\end{array}$ & $\begin{array}{c}\{\alpha=3 ; \beta=1 ; \gamma=0.25\} \\
y \leq 15 \%\end{array}$ & $\begin{array}{c}1 / \mathrm{m} \\
y=6.25 \%\end{array}$ \\
\hline $\begin{array}{l} \\
\text { STOCK }\end{array}$ & $\begin{array}{l}0.0000 \\
0.0016\end{array}$ & $\begin{array}{l}0.0002 \\
0.6536\end{array}$ & $\begin{array}{l}0.0005 \\
0.0006\end{array}$ & $\begin{array}{l}0.0004 \\
0.0018\end{array}$ & $\begin{array}{l}0.0005 \\
0.7177\end{array}$ & $\begin{array}{l}0.0002 \\
0.0003\end{array}$ & $\begin{array}{l}0.0005 \\
0.0000\end{array}$ \\
\hline DEF & 0.0097 & 0.0649 & 0.0353 & 0.0671 & 0.0889 & 0.0398 & 0.0677 \\
\hline LIQU & 0.3550 & 0.3830 & 0.6723 & 0.4734 & 0.3886 & 0.5297 & 0.6060 \\
\hline TERM & 0.0511 & 0.0512 & 0.1633 & 0.0713 & 0.0678 & 0.0770 & 0.0969 \\
\hline $\begin{array}{l}\text { TREND } \\
\text { TREN }\end{array}$ & 0.0014 & 0.0049 & $\begin{array}{l}0.10249 \\
0.0250\end{array}$ & 0.0119 & 0.0112 & 0.0098 & 0.0123 \\
\hline
\end{tabular}

\begin{tabular}{|c|c|c|c|c|c|c|c|}
\hline & \multirow{2}{*}{\multicolumn{7}{|c|}{$\frac{\text { PANEL B }}{\text { CFO 11 }}$}} \\
\hline & & & & & & & \\
\hline & & & & \multicolumn{3}{|l|}{ coefficients } & \\
\hline & $\begin{array}{c}\{a=1 ; \beta=0 ; \gamma=0\} \\
y \leq 100 \%\end{array}$ & $\begin{array}{c}\{\alpha=1 ; \beta=1 ; \gamma=0\} \\
y \leq 100 \%\end{array}$ & $\begin{array}{c}\{\alpha=1 ; \beta=1 ; \gamma=0\} \\
y \leq 20 \%\end{array}$ & $\begin{array}{c}\{\alpha=2 ; \beta=1 ; \gamma=0.75\} \\
y \leq 10 \%\end{array}$ & $\begin{array}{c}\{\alpha=3 ; \beta=1 ; \gamma=0.25\} \\
y \leq 50 \%\end{array}$ & $\begin{array}{c}\{\alpha=3 ; \beta=1 ; \gamma=0.25\} \\
y \leq 15 \%\end{array}$ & $\begin{array}{c}1 / \mathrm{m} \\
y=6.25 \%\end{array}$ \\
\hline & 0.037932 & 0.031745 & 0.035875 & 0.037632 & 0.030135 & 0.038319 & 0.038088 \\
\hline & & & & 0.122659 & & & 0.217518 \\
\hline DEF & -0.001056 & -0.000803 & -0.001073 & -0.000942 & -0.000749 & -0.001033 & -0.000944 \\
\hline LILQ & -49.959631 & -46.930344 & -35.537299 & -49.574431 & -48.093856 & -45.137863 & -41.680773 \\
\hline TERN & -3.254628 & -3.444272 & -2.654086 & -3.858305 & -3.212852 & -3.641032 & -3.606458 \\
\hline \multirow[t]{3}{*}{ TREND } & -0.000253 & -0.000230 & -0.000217 & -0.000250 & -0.000211 & -0.000249 & -0.000257 \\
\hline & \multicolumn{7}{|c|}{ p-values } \\
\hline & $\begin{array}{c}\{\alpha=1 ; \beta=0 ; y=0\} \\
y \leq 100 \%\end{array}$ & $\left\{\begin{array}{c}\{=1 ; \beta=1 ; y=0\} \\
y \leq 100 \%\end{array}\right.$ & $\left\{\begin{array}{c}\alpha=1 ; \beta=1 ; y=0\} \\
y \leq 20 \%\end{array}\right.$ & $\begin{array}{c}\{a=2 ; \beta=1 ; \gamma=0.75\} \\
y \leq 10 \%\end{array}$ & $\begin{array}{c}\{\alpha=3 ; \beta=1 ; \gamma=0.25\} \\
y \leq 50 \%\end{array}$ & $\begin{array}{c}\{\alpha=3 ; \beta=1 ; y=0.25\} \\
y \leq 15 \%\end{array}$ & $\begin{array}{c}1 / \mathrm{m} \\
y=6.25 \%\end{array}$ \\
\hline & 0.0000 & 0.0013 & 0.0013 & 0.0011 & 0.0024 & 0.0006 & 0.0017 \\
\hline & $\begin{array}{l}0.0015 \\
0.0119\end{array}$ & $\begin{array}{l}0.4848 \\
0.0744\end{array}$ & $\begin{array}{l}0.0005 \\
0.0353\end{array}$ & $\begin{array}{l}0.0019 \\
0.0738\end{array}$ & $\begin{array}{l}0.8991 \\
0.0986\end{array}$ & $\begin{array}{l}0.0002 \\
0.0429\end{array}$ & 0.0000 \\
\hline & 0.1794 & 0.2437 & 0.4326 & 0.2925 & 0.2362 & 0.3205 & 0.3996 \\
\hline & 0.0861 & 0.0935 & 0.2495 & 0.1082 & 0.1203 & 0.1162 & 0.1529 \\
\hline TREND & 0.0005 & 0.0032 & 0.0131 & 0.0061 & 0.0073 & 0.0047 & 0.0073 \\
\hline
\end{tabular}

\begin{tabular}{|c|c|c|c|c|c|c|c|}
\hline & \multicolumn{7}{|c|}{ CFO 15} \\
\hline & \multicolumn{7}{|c|}{ coefficients } \\
\hline & $\begin{array}{c}\{\alpha=1 ; \beta=0 ; \gamma=0\} \\
y \leq 100 \%\end{array}$ & $\left\{\begin{array}{c}\{\alpha=1 ; \beta=1 ; \gamma=0\} \\
y \leq 100 \%\end{array}\right.$ & $\left\{\begin{array}{c}\{\alpha=1 ; \beta=1 ; \gamma=0\} \\
y \leq 20 \%\end{array}\right.$ & $\begin{array}{c}\{\alpha=2 ; \beta=1 ; \gamma=0.75\} \\
y \leq 10 \%\end{array}$ & $\begin{array}{c}\{\alpha=3 ; \beta=1 ; \gamma=0.25\} \\
y \leq 50 \%\end{array}$ & $\begin{array}{c}\{\alpha=3 ; \beta=1 ; \gamma=0.25\} \\
y \leq 15 \%\end{array}$ & $\begin{array}{c}1 / \mathrm{m} \\
y=6.25 \%\end{array}$ \\
\hline $\begin{array}{l} \\
\text { STOCK } \\
\text { DEF } \\
\text { LIQU } \\
\text { TERM } \\
\text { TREND } \\
\end{array}$ & $\begin{array}{c}0.050856 \\
0.138615 \\
-0.001428 \\
-81.2544111 \\
-4.251777 \\
-0.000370 \\
\end{array}$ & $\begin{array}{c}0.044229 \\
-0.044203 \\
-0.001170 \\
-76.995044 \\
-4.744886 \\
-0.000350 \\
\end{array}$ & $\begin{array}{c}0.048016 \\
0.191964 \\
-0.001481 \\
-62.397691 \\
-3.253458 \\
-0.000320 \\
\end{array}$ & $\begin{array}{c}0.050308 \\
0.169802 \\
-0.001271 \\
-80.775945 \\
-5.024286 \\
-0.000366 \\
\end{array}$ & $\begin{array}{l}0.041476 \\
-0.003430 \\
-0.001080 \\
-79.772810 \\
-4.336980 \\
-0.000318 \\
\end{array}$ & $\begin{array}{c}0.051277 \\
0.201255 \\
-0.001401 \\
-75.565411 \\
-4.723197 \\
-0.000364 \\
\end{array}$ & $\begin{array}{l}0.049340 \\
0.316547 \\
-0.001199 \\
-69.526505 \\
-4.471656 \\
-0.000368 \\
\end{array}$ \\
\hline & \multicolumn{7}{|c|}{ p-values } \\
\hline & $\begin{array}{c}\{\alpha=1 ; \beta=0 ; \gamma=0\} \\
y \leq 100 \%\end{array}$ & $\begin{array}{c}\{=1 ; \beta=1 ; \gamma=0\} \\
y \leq 100 \%\end{array}$ & $\left\{\begin{array}{c}\{=1 ; \beta=1 ; \gamma=0\} \\
y \leq 20 \%\end{array}\right.$ & $\begin{array}{c}\{\alpha=2 ; \beta=1 ; y=0.75\} \\
y \leq 10 \%\end{array}$ & $\begin{array}{c}\{a=3 ; \beta=1 ; \gamma=0.25\} \\
y \leq 50 \%\end{array}$ & $\left\{\begin{array}{c}\{\alpha=3 ; \beta=1 ; y=0.25\} \\
y \leq 15 \%\end{array}\right.$ & $\begin{array}{c}1 / \mathrm{m} \\
y=6.25 \%\end{array}$ \\
\hline & & 0. & & 0.0 & $\overline{0 . c}$ & 0.0011 & 0.0037 \\
\hline DC & & & & & & & $\begin{array}{l}0.0000 \\
0.1235\end{array}$ \\
\hline & & & & & & & 0.3185 \\
\hline & & & & & 0.1594 & & 0.2073 \\
\hline & 0.0004 & 0.0029 & 0.0099 & 0.0045 & 0.0066 & 0.0034 & \\
\hline
\end{tabular}

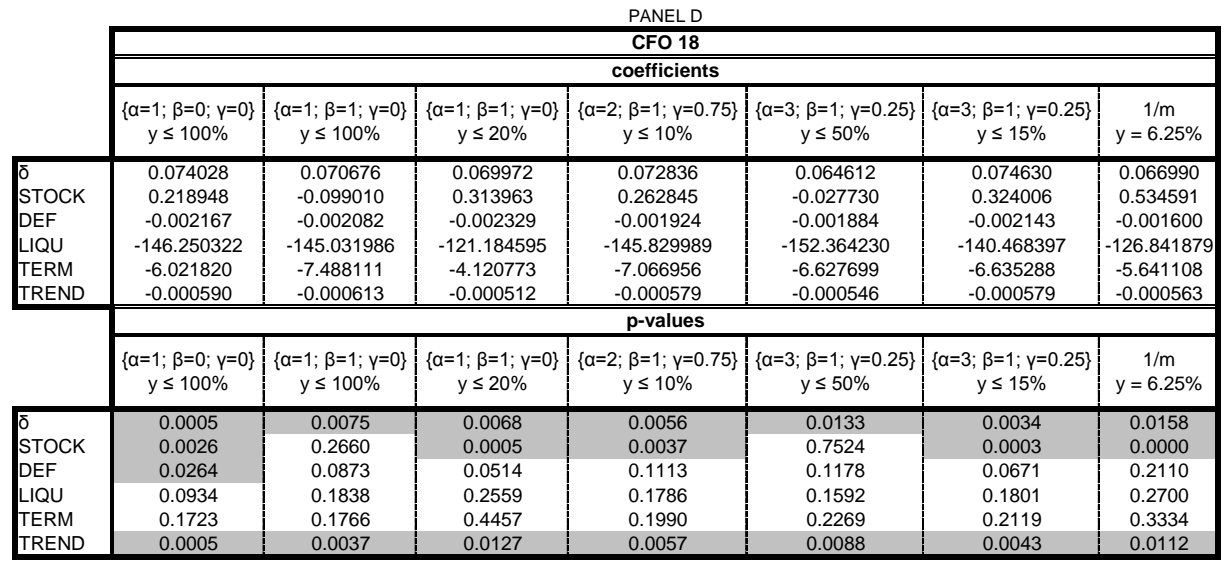

